\title{
Pyruvate metabolism controls epigenome remodeling during CD4+ $T$ cell activation
}

\section{Enric Mocholi}

Albert Einstein College of Medicine

\section{Laura Russo}

University Medical Center Utrecht

\section{Keshav Gopal}

University of Alberta

\section{Andrew Ramstead}

University of Utah

\section{Sophia M. Hochrein}

Würzburg Institute of Systems Immunology

\section{HarmJan Vos}

Oncode Institute and Molecular Cancer Research, Center for Molecular Medicine, University Medical Center Utrecht

\section{Geert Geeven}

Erasmus MC-University Medical Center

\section{Adeolu Adegoke}

University of Alberta https://orcid.org/0000-0003-0886-9678

\section{Anna Hoekstra}

\section{Utrecht University}

\section{Robert van Es}

Oncode Institute and Molecular Cancer Research, Center for Molecular Medicine, University Medical Center Utrecht

José Ramos Pittol

University of Innsbruck https://orcid.org/0000-0003-3753-5394

\section{Sebastiaan Vastert}

UMC Utrecht

\section{Jared Rutter}

University of Utah, School of Medicine, Department of Biochemistry, Salt Lake City, United States https://orcid.org/0000-0002-2710-9765

\section{Timothy Radstake}

University Medical Center Utrecht

\section{Jorg van Loosdregt}

University Medical Center Utrecht 


\section{Celia Berkers}

Utrecht University https://orcid.org/0000-0003-0746-8565

\section{Michal Mokry}

University Medical Center Utrecht https://orcid.org/0000-0002-5298-4852

\section{Colin Anderson}

University of Alberta https://orcid.org/0000-0003-1733-4237

\section{Ryan O'Connell}

University of Utah https://orcid.org/0000-0003-0860-1401

\section{Martin Vaeth}

Würzburg Institute of Systems Immunology, Max-Planck Research Group, University Würzburg https://orcid.org/0000-0001-8974-7052

\section{John Ussher}

University of Alberta https://orcid.org/0000-0001-9574-5707

\section{Boudewijn Burgering}

University Medical Center Utrecht https://orcid.org/0000-0002-4044-9596

\section{Paul Coffer ( $\boldsymbol{Q}$ P.J.Coffer@umcutrecht.nl )}

University Medical Center Utrecht https://orcid.org/0000-0001-8775-1939

\section{Article}

\section{Keywords:}

Posted Date: February 14th, 2022

DOI: https://doi.org/10.21203/rs.3.rs-1324599/v1

License: (c) (1) This work is licensed under a Creative Commons Attribution 4.0 International License. Read Full License 


\title{
Pyruvate metabolism controls epigenome remodeling during $\mathrm{CD4}^{+} \mathrm{T}$ cell activation
}

\author{
Enric Mocholi 1,2,*, Laura Russo ${ }^{1,2}$, Keshav Gopal ${ }^{3 \#, ~ A n d r e w ~ G . ~ R a m s t e a d " \#, ~}$ \\ Sophia M. Hochrein ${ }^{5 \#}$, Harmjan R. Vos ${ }^{1 \#}$, Geert Geeven ${ }^{6}$, Adeolu Adegoke ${ }^{7}$, Anna \\ Hoekstra ${ }^{8}$, Robert M. van Es ${ }^{1}$, Jose Ramos Pittol ${ }^{1}$, Sebastian Vastert ${ }^{9}$, , Jared \\ Rutter $^{4}$, Timothy Radstake $e^{9,10}$, Jorg van Loosdregt ${ }^{9}$, Celia Berkers ${ }^{8,11}$, Michal \\ Mokry2,12, Colin Anderson 7 , Ryan M. O'Connell ${ }^{4+}$, Martin Vaeth ${ }^{5+}$, John Ussher ${ }^{3+}$, \\ Boudewijn MT Burgering ${ }^{1+}$ and Paul J Coffer ${ }^{1,2^{*}}$
}

${ }^{1}$ Center for Molecular Medicine, University Medical Center Utrecht, 3584 Utrecht, the Netherlands.

${ }^{2}$ Regenerative Medicine Center, University Medical Center, Utrecht, Utrecht, The Netherlands.

${ }^{3}$ Faculty of Pharmacy and Pharmaceutical Sciences, University of Alberta, Edmonton, Alberta, Canada.

${ }^{4}$ Huntsman Cancer Institute and the Division of Microbiology and Immunology, Department of Pathology at the University of Utah, 15 N. Medical Dr. East, Salt Lake City, UT, 84112, USA.

${ }^{5}$ Würzburg Institute of Systems Immunology, Max Planck Research Group at the Julius-

Maximilians University of Würzburg, Würzburg, Germany

${ }^{6}$ Department of Clinical Genetics, Erasmus MC-University Medical Center, Rotterdam, Netherlands

${ }^{7}$ Department of Surgery, University of Alberta, Edmonton, AB, Canada.

${ }^{8}$ Biomolecular Mass Spectrometry and Proteomics, Bijvoet Center for Biomolecular Research, Utrecht University, Padualaan 8, 3584 CH Utrecht, The Netherlands

${ }^{9}$ Laboratory for Translational Immunology and Department of Pediatric Rheumatology and Immunology, University Medical Center Utrecht, 3584 Utrecht, the Netherlands.

10 Department of Rheumatology and Clinical Immunology, University Medical Center Utrecht, Utrecht, The Netherlands

11 Department of Biochemistry and Cell Biology, Faculty of Veterinary Medicine, Utrecht University, Yalelaan 2, 3584 CM Utrecht, the Netherlands

${ }^{12}$ Cardiovascular Genetics, University Medical Center, Utrecht, Utrecht, The Netherlands

+ equal senior author contribution

\# equal contribution

* corresponding authors 


\begin{abstract}
Upon antigen-specific $\mathbf{T}$ Cell Receptor (TCR) engagement, human CD4 $^{+} \mathbf{T}$ cells proliferate and differentiate, a process associated with rapid transcriptional changes and metabolic reprogramming. Here, we show that generation of extra-mitochondrial pyruvate is an essential step for acetyl-CoA production and subsequent H3K27acmediated epigenome remodeling. In contrast, neither acetate/ACSS2 nor citrate/ACLY metabolism are required for activation-induced transcriptional changes. Furthermore, $T$ cell activation results in the nuclear translocation of PDC and its association with both the p300 acetyltransferase and histone H3K27ac. These data support tight integration of metabolic and histone-modifying enzymes, allowing metabolic reprogramming to fuel CD4+ $T$ cell activation. Targeting this pathway may provide a novel therapeutic approach to specifically regulate antigen-driven $T$ cell activation.
\end{abstract}




\section{Introduction}

The immune system comprises specialized cell populations that are conditioned to respond rapidly to antigenic and inflammatory signals. While research has focused on these signals in guiding immune responses, emerging data indicate that cellular metabolism is critical in moderating immune cell function and differentiation, consequently influencing the outcome of the adaptive and innate immune response [1-4]. Engagement of the T Cell Receptor (TCR), concurrently with the recognition of costimulatory molecules by the receptor CD28 triggers T cell activation characterized by transcriptional reprogramming, clonal expansion, and differentiation to effector phenotypes [5]. These changes in the activation status of CD4 ${ }^{+} \mathrm{T}$ lymphocytes not only require energy, but also increase demand for metabolic precursors for the biosynthesis of proteins, nucleic acids, and lipids. Therefore, efficient $\mathrm{T}$ cell activation requires profound changes in intracellular metabolism [6, 7].

T cell homeostasis is characterized by the metabolism of glucose, fatty acids, and amino acids to generate intermediate metabolites, which can enter the mitochondrial TCA cycle [8]. Upon antigen recognition, $T$ cells rapidly upregulate aerobic glycolysis, but not at the expense of oxidative metabolism, to support bioenergetic demands [8-10]. While the metabolism of proliferating $T$ cells is adapted to facilitate uptake and incorporation of nutrients into the biomass needed to produce a daughter cell [11-13], it has been shown that carbon compound biosynthesis from glucose does not contribute to most of the carbon in proliferating T cells [14]. Hand-in-hand with activation-induced metabolic changes, epigenome reprogramming and regulation of transcriptional output are essential for $\mathrm{T}$ cell expansion and differentiation. Underlying this, histone acetylation results in a more accessible chromatin structure permissive to transcriptional machinery. This requires the availability of acetyl-CoA, which is the sole source of acetyl groups in eukaryotic cells [15]. Regulation of acetyl-CoA synthesis, which can be produced from acetate, citrate, or pyruvate serves as a critical rate-limiting step for histone acetyltransferase (HAT) activity within cells [16-18]. Notably, in CD4 ${ }^{+} \mathrm{T}$ cells, it has been demonstrated that deletion of lactate dehydrogenase A (LDHA) inhibited glycolytic metabolism, reduced acetyl-CoA levels, and lowered H3K9ac of the Ifng enhancer [19]. However, it remains unclear how LDHA deficiency directly modulates acetyl-CoA levels, whether by reducing levels of citrate available for conversion to acetyl-CoA or through inhibition of acetyl-CoA synthetase [19]. Flavell and co-workers have proposed a role for mitochondrial metabolism in regulating H3K9 acetylation in differentiated murine CD4 ${ }^{+}$Th1 cells [20]. T cells have also recently been shown to remodel the epigenome through metabolizing acetate in an acetyl-CoA synthetase (ACSS)-dependent manner during conditions of glucose restriction [21]. Furthermore, polyamine metabolism has also been shown to be critical for the ability of CD4 ${ }^{+}$helper T cells to differentiate, a process that takes several days after initial activation [22].

$\mathrm{CD}^{+} \mathrm{T}$ cells are metabolically flexible and have multiple mechanisms to ensure acetyl-CoA generation required for epigenome remodeling and transcription. However, it remains unclear whether there is a requirement for specificity in terms of the metabolic pathways that generate (nuclear) acetyl-CoA, and whether these pathways play a deterministic role in gene transcription. Here, we have explored the metabolic pathways required for TCR-mediated transcriptional activation during the first 24 hours of $\mathrm{CD}^{+}{ }^{+} \mathrm{T}$ cell activation. Our results demonstrate that after TCR engagement, extra-mitochondrial pyruvate, as an end-product of glycolysis, but not citrate or acetate, is essential for driving remodeling of the $\mathrm{CD}^{+} \mathrm{T}$ cell epigenome. This is critical for the expression of activation-dependent transcription. CD4 ${ }^{+} \mathrm{T}$ cell activation also leads to nuclear translocation of pyruvate dehydrogenase and its association with histones and HATs, potentially resulting in localized acetyl-CoA production. Our findings highlight the intimate link between metabolism, transcription, and T cell function. The influence of metabolic alterations in inflammatory environments may allow the design of novel interventions to specifically target these pathways to mitigate inflammatory disorders and autoimmunity, in which T cells play a pathophysiological role. 


\section{Results}

\section{Glucose-derived acetyl-CoA is essential for TCR-induced epigenome remodeling and transcription}

T cell activation is known to require a metabolic shift towards glycolysis, triggered by TCRengagement $[6,23]$. To re-evaluate the role of glycolysis in transcriptional reprogramming during antigen-driven $\mathrm{T}$ cell activation, we utilized a well-established ex-vivo model to recapitulate the process of antigen stimulation without the requirement for additional antigenpresenting cells $[24,25]$. Here, we initially wished to further explore and validate the conditions for both metabolic and epigenetic reprogramming. Antigen-mediated $\mathrm{CD} 4^{+} \mathrm{T}$ cells activation initiates context-specific gene-expression programs that drive effector functions and cell fates through changes in the epigenetic landscape [26]. To evaluate global changes in histone modifications, we isolated CD4 ${ }^{+} \mathrm{T}$ cells from peripheral blood (PB) of healthy control $(\mathrm{HC})$ human donors and either maintained them in resting conditions or stimulated with antiCD3/CD28 for 12, 24, and 48h. Total levels of H3AcK27, H3K4m1, H3K27m3, and H3K4met3 did not change during the activation (Figure S1A-B). However, as expected, rapid changes in the $\mathrm{CD}^{+}$epigenome and transcriptome were observed within $24 \mathrm{~h}$ as measured by RNAsequencing (RNA-seq) and H3K27ac chromatin immunoprecipitation followed by DNAsequencing (ChIP-seq) (Figure S2A-D). Upon T cell activation, increased H3K27ac levels at enhancer-promoters directly correlated with the expression of associated genes (Figure S2EG). Notably, the metabolic genes regulating glycolysis also demonstrated both increased activation-induced H3K27ac and RNA levels, supporting a positive feedback loop for enforcing and stabilizing metabolic reprograming (Figure S3A-B).

To explore the requirement for metabolic reprogramming in regulating transcriptional responses after initial TCR-engagement, $\mathrm{CD}^{+}{ }^{+} \mathrm{T}$ cells from peripheral blood of healthy donors were isolated and activated in either the presence or absence of oligomycin (inhibitor of ATP synthase blocking the production of ATP by OXPHOS), 2DG (competitively inhibiting production of glucose-6-phosphate from glucose), or replacement of glucose with galactose. Galactose is metabolized through glycolysis, utilizing the Leloir pathway which is energy neutral, forcing cells to use all the pyruvate production to sustain the TCA cycle for OXPHOS and ATP synthesis at the expense of lactate production [27-29]. We were again unable to detect significant global changes in histone modifications as a consequence of metabolic inhibition (Figure 1A, S4A). Employing ChIP-seq and RNA-seq, inhibition of OXPHOSmediated ATP production by oligomycin had only a limited effect on H3K27-acetylation or activation-induced transcription during the first $24 \mathrm{~h}$ of activation (Figure 1B-C, S4B). This is supported by studies that have shown decreased utilization of glucose-derived carbon for mitochondrial metabolism after $\mathrm{T}$ cell activation [8, 19]. In contrast, inhibition of glycolysis by 2DG treatment compromised both H3K27-acetylation and transcriptional changes (Figure 1B, 1D, S4C). In the context of murine Th1 cells, the generation of lactate has been found to increase acetyl-CoA levels and $\mathrm{H} 3 \mathrm{~K} 9$ acetylation at the IFN- $\gamma$ enhancer [19]. However, under conditions of galactose-metabolism where lactate-production is abrogated, activated CD4 ${ }^{+} \mathrm{T}$ cells were still able to globally remodel H3K27 acetylation and reprogram the transcriptome (Figure 1B, 1E, S4D, S11B). Principle component analysis (PCA) of H3K27ac ChIP-seq and RNAseq analyses suggest that activation-induced H3K27ac changes and transcription are dependent on the conversion of glucose to pyruvate, and independent of the production of lactate (Figure 1B, S4E).

Identification of activation-induced genes, as defined by increased H3K27-acetylation $(\leq 5 \mathrm{~kb}$ away from their TSS), in the absence or presence of 2DG, identified a subset that depends on increased glycolysis (Figure S4F). GO-term analysis reveals that these are critical players in $T$ cell activation and include interleukin receptors, $C D$ markers, and other genes associated with T cell activation (Figure S5A-B). IL2RA, SEMA7A, and CD38 are examples of this group 
of genes and were used as surrogate activation markers for further analysis (Figure S5C). To validate that these genes are dependent on glycolysis during $T$ cell activation, we activated human $\mathrm{CD}^{+} \mathrm{T}$ cells in presence of $2 \mathrm{DG}$ or the absence of glucose and measured cell-surface and RNA expression of CD25, CD38, or SEMA7A (Figure S6A-B). It is clear that access to glucose and initiation of glycolysis is a requirement for the expression of these genes.

To evaluate the role of glucose-derived acetyl-CoA in changes in H3K27ac we first measured acetyl-CoA levels in $\mathrm{CD}^{+} \mathrm{T}$ cells under resting or activated conditions in the presence or absence of oligomycin or 2DG. Increased acetyl-CoA levels were observed after activation and were primarily dependent on glycolytic metabolism (Figure 1F). Additionally, T cells were stimulated with anti-CD3/CD28 in presence of heavy glucose (D-Glucose $-{ }^{13} \mathrm{C}_{6}$ ), and the levels of isotopically-coded acetyl groups on H3K27 were measured by LC-MS. CD4 ${ }^{+}$T cell activation resulted in an increase of ${ }^{13} \mathrm{C}_{2}$ incorporation in acetylated $\mathrm{H} 3 \mathrm{~K} 27$ histones that is abrogated by the addition of 2DG (Figure 1G, S6C). Taken together, these data demonstrate that during the early phase of antigen-driven T cell activation, glycolysis is essential for acetyl-CoA production, H3K27ac-mediated chromatin remodeling, and transcriptional reprogramming, independently of lactate production.

\section{Acetate and citrate metabolism are not required for TCR-induced epigenome remodeling}

To evaluate the potential role of intermediate glycolytic metabolites in the generation of acetyl$\mathrm{CoA}$ and histone remodeling, we first evaluated the expression levels of enzymes generating acetyl-CoA. Human CD4 ${ }^{+}$T cells were stimulated with anti-CD3/CD28 and the level of ATP citrate synthase (ACLY), acyl-coenzyme A synthetase short-chain family member 2 (ACSS2), and pyruvate dehydrogenase alpha 1 (PDC-E1) were measured (Figure 2A; Figures S7A). Expression of ACLY and ACSS2 were low in resting cells and during the first $16 \mathrm{~h}$ of activation while increasing after 24 hours of stimulation. In contrast, PDC-E1 expression was already present in resting cells and was subsequently upregulated. A recent study provided evidence that activated T cells during 5 or 9 days are also able to remodel the epigenome in an acetylCoA synthetase (ACSS)-dependent manner during glucose restriction [21].To evaluate this in the first $24 \mathrm{~h}$ of activation, T cells were activated in the presence or absence of an inhibitor of acetyl-CoA synthetase 2 (ACSS2). Inhibition of ACSS2 did not prevent TCR-mediated increases in CD25, protein, or mRNA expression during this first 24h of activation. These data suggest that acetate-derived acetyl-CoA might play a non-essential role in transcriptional regulation in the presence of glucose during the first $24 \mathrm{~h}$ of $\mathrm{T}$ cell activation (Figure 2B-C). Furthermore, provision of exogenous acetate during $24 \mathrm{~h} T$ cell activation was not sufficient to rescue IL2RA expression under conditions where glycolysis was inhibited (Figure 2D).

To evaluate the role of $A C L Y$ in transcriptional reprogramming, CD4 ${ }^{+} \mathrm{T}$ cells were activated $24 \mathrm{~h}$ in the presence or absence of ACLY inhibitors (SB204990 or BMS303141). Cell-surface protein and mRNA expression of CD25, CD38, or SEMA7A were again evaluated. ACLY inhibition did not prevent TCR-mediated expression supporting the notion that citrate-derived acetyl-CoA is not fundamental for the transcriptional regulation of T cells during the first $24 \mathrm{~h}$ of activation (Figure 2E-F, S8A-B). To genetically confirm that ACLY is not required for activation-induced epigenome remodeling, we utilized $\mathrm{CD}^{+}{ }^{+} \mathrm{T}$ cells from conditional knockout mice with T cell-specific ablation of ACLY (CD4-Cre ACLY/f/fl) (Figure 2G). To evaluate the impact of the loss of ACLY in regulating transcriptional responses after TCR-engagement, ACLY-deficient or WT CD4 ${ }^{+} \mathrm{T}$ cells were stimulated with anti-CD3/CD28, and expression of CD25 was evaluated (Figure 2H-I). ACLY-deletion did not affect TCR-mediated upregulation of CD25 expression. We subsequently performed global transcriptomics using RNAsequencing (RNA-seq). Gene expression profiles of WT and ACLY-deficient T cells were very similar with few differences (Figure 2J, S8C). In addition, Gene Set Enrichment Analysis (GSEA) demonstrates that the transcriptional changes observed after ACLY-deletion do not correlate with either genes upregulated during the first $24 \mathrm{~h}$ of $\mathrm{T}$ cell activation, or with genes 
down-regulated upon inhibition of glycolysis (Figure $\mathbf{2 K}-\mathrm{L}$ ). These data confirm that ACLY is not required for transcriptional regulation during the initial phase of human and mouse CD4 ${ }^{+} \mathrm{T}$ cell activation. Taken together these data show that histone acetylation and gene expression in the initial phase of $T$ cell activation depends neither on acetate metabolism nor citrate metabolism.

\section{Pyruvate dehydrogenase is required for activation-induced transcriptional reprogramming and $T$ cell function}

Our data suggest that neither ACSS2 nor ACLY plays a central role in driving chromatin remodeling and transcriptional reprogramming during the first $24 \mathrm{~h}$ of $\mathrm{T}$ cell activation. To evaluate the role of pyruvate metabolism, we first evaluated intracellular pyruvate levels during $T$ cell activation. $\mathrm{CD}^{+}{ }^{+} \mathrm{T}$ cells were stimulated with anti-CD3/CD28 in the presence of $\mathrm{D}$ Glucose- ${ }^{13} \mathrm{C} 6$, and intracellular ${ }^{13} \mathrm{C}$-pyruvate levels were measured by LC-MS mass spectrometry (Figure 3A). Maximal pyruvate levels were observed 16hrs after activation. To evaluate whether pyruvate is a critical glycolytic intermediate regulating the expression of activation-induced genes, we performed a rescue experiment by activating CD4+ ${ }^{+}$cells in the presence or absence of 2DG, or 2DG together with pyruvate. The addition of pyruvate was sufficient to rescue IL2RA-, CD38- and SEMA7A-associated H3K27 acetylation under conditions where glycolysis was inhibited (Figure 3B, S9A).

To evaluate whether pyruvate dehydrogenase is critical for activation-induced histone acetylation, we utilized 6,8-Bis (benzylthio)octanoic acid, an inhibitor of PDC activity [30]. CD4+ $T$ cells activated in presence of 6,8-Bis(benzylthio)octanoic acid showed no increase in $C D 25$, SEMA7A- and CD38-associated H3K27 promoter-acetylation (Figure 3C, S9B) and, consequently, abolished cell surface expression of these markers (Figure 3D, Figure S9C). Furthermore, the addition of pyruvate was no longer sufficient to rescue CD25-, CD38- and SEMA7A-associated H3K27 promotor acetylation, or cell-surface expression (Figure 3C-D, S9B-C). To further validate our inhibitor data, we performed siRNA-mediated PDHA1 knockdown in human $\mathrm{CD} 4^{+} \mathrm{T}$ cells, with an efficiency of around $50 \%$ (Figure $3 \mathrm{E}$ ). PDHA1 knock-down CD4 ${ }^{+}$T cells show a clear decrease in expression of IL2RA, SEMA7A, and CD38 (Figure 3F, S9D). Taken together, these data suggest that the generation of pyruvate is both necessary and sufficient for $T$ cell activation-induced regulation of H3K27ac and the expression of target genes.

To confirm pyruvate dehydrogenase plays a fundamental role in antigen-driven transcriptional reprogramming of CD4 ${ }^{+}$T cells, we generated a T cell-specific and inducible PDHA1 knockout mouse by crossing PDHA $1^{\mathrm{fl} / \mathrm{fl}}$ mouse with CD4 ${ }^{\mathrm{CreERT}}$. PDC-E1, generated from the PDHA1 gene, is an essential subunit of the pyruvate dehydrogenase complex catalyzing three reaction steps necessary for the full conversion of pyruvate to acetyl-CoA. To induce PDHA1-deletion, animals were treated with tamoxifen for five days, and after three weeks a reduction of $P D H A 1$ mRNA and PDCE1 protein was observed (Figure S10A-B). Expression of PDC-E2 was unaffected (Figure S10A-B). PDHA $1^{\mathrm{fl/f}} \mathrm{Cd} 4^{\mathrm{CreERT2}}$ mice had a normal spleen size (Figure 3G) and there were no significant differences in splenic populations of CD45, CD8, B cells, and macrophages compared to WT mice (Figure 3H, S10C). A small but significant reduction of total numbers of $\mathrm{CD} 4^{+} \mathrm{T}$ cells and a moderate increase of naïve $\mathrm{CD} 4^{+} \mathrm{T}$ cells were observed (Figure $3 \mathrm{H}, \mathbf{S 1 0 C}$ ). The effect of PDHA1 deletion on T cell metabolism was evaluated by Seahorse extracellular flux analyses. Activated $T$ cells show a moderate but significant reduction of mitochondrial respiration and maximal respiration (Figure S10D-F). This demonstrates that under these conditions, the TCA cycle can be supported independently of pyruvate metabolism. Additionally, disruption of the PDC does not have a significant effect on the glycolytic lactate production (Figure S10G) [31].

To explore the impact of T cell-specific PDC-disruption on the regulation of transcriptional responses after TCR-engagement, $P D H A 1$-deficient or WT CD4 ${ }^{+}$T cells were stimulated with anti-CD3/CD28 for $24 \mathrm{~h}$, and CD25 cell-surface protein and mRNA expression were evaluated 
(Figure 31-J). PDHA1-deletion resulted in a decrease of both IL2RA and CD25 expression compared to CD4 ${ }^{\mathrm{ERT} 2}$ controls. The absence of $P D H A 1$ also compromised transcriptome reprogramming during $T$ cell activation as measured by RNA-seq (Figure $3 \mathrm{~K}$ ). There was a clear correlation between the expression of genes affected by the loss of PDHA1 and genes that are upregulated during $T$ cell activation and downregulated in presence of 2DG (Figure 3L-M). Importantly, evaluating the expression of a subset of $\mathrm{T}$ cell activation marker genes, loss of PDHA1, but not ACLY, was clearly detrimental (Figure $3 \mathbf{N}$ ).

To evaluate the effect of disrupting PDC in $\mathrm{CD}^{+} \mathrm{T}$ cells on peripheral $\mathrm{T}$ cell responses, we utilized the experimental autoimmune encephalomyelitis (EAE) model, which is dependent on $\mathrm{CD}^{+}{ }^{+}$T cells. Here, WT (CD4 ${ }^{\text {CreERT2 }}$ ) or mice with T cell-specific deletion of PDHA1 (CD4 ${ }^{\text {CreERT2 }}$ $\left.P D H A 1^{f / 1 / 1 \mid}\right)$ were injected subcutaneously with $\mathrm{MOG}_{35-55}$ peptide followed by i.p. injection with pertussis toxin on days 0 and 2, and clinical progression of the paralysis was scored during 21 days. Mice lacking PDHA1 in $\mathrm{CD}^{+} \mathrm{T}$ cells had diminished severity of disease progression compared with CD4 $4^{\text {CreERT2 }}$ littermates (Figure 30) at the later time points, consistent with $P D H A 1$-deficient $\mathrm{CD} 4^{+}$cells having reduced functionality.

Taken together these data support an essential role for pyruvate dehydrogenase activity in driving $\mathrm{CD}^{+} \mathrm{T}$ cell activation and transcriptional reprogramming.

\section{Mitochondrial pyruvate uptake is not required for activation-induced epigenome remodeling and $\mathrm{CD4}^{+} \mathrm{T}$ cell function}

Our previous results show that during the first $24 \mathrm{~h}$ of TCR engagement, ACCS2 and ACLY do not play essential roles in regulating epigenomic and transcriptomic changes. However, loss of PDC activity has a dramatic effect on the upregulation of activation-induced genes. In eukaryotes, biosynthesis of acetyl-CoA is thought to occur in the subcellular compartment where it is required, since it is both membrane-impermeable and unstable, due to the high energy thioester bond that joins the acetyl and CoA groups [27, 32-34]. The major role for PDC is metabolizing pyruvate to acetyl CoA in the mitochondria driving the TCA cycle. To interrogate this, we activated human CD4+ ${ }^{+}$cells in the presence or absence of 2DG, 3PO ((2E)-3-(3Pyridinyl)-1-(4-pyridinyl)-2-propen-1-one, PFKFB3 inhibitor), UK5099 (mitochondrial pyruvate carrier inhibitor) or with DCA (dichloroacetate, pyruvate dehydrogenase kinase (PDK) inhibitor) (Figure S11A-C). No drug-induced differences in $\mathrm{CD}^{+} \mathrm{T}$ cell viability were observed (Figure S11D-F). ChIP-qPCR analysis revealed that activation of $C D 4^{+} T$ cells in the presence of 2DG or 3PO (inhibitors of glycolysis) prevented CD25-, CD38- or SEMA7A-associated H3K27acetylation and transcription (Figure 4A-B, S12A-B), and inhibited cell-surface protein expression (Figure 4C, S12C, S6A). CD4 ${ }^{+} T$ cells activated in presence of DCA (which promotes TCA cycle metabolism thereby reducing lactate production), or in presence of UK5099 (inhibitor of mitochondrial pyruvate import and promotor of lactate production) had no effect (Figure 4A-C, S12A-C). To eliminate the possibility that MPC2 was working as an autonomous membrane carrier [35], $T$ cells were activated in the presence of the thiazolidinedione-derivative rosiglitazone, which can inhibit MPC2 activity [36, 37]. Rosiglitazone-treatment also did not affect TCR-mediated increases in CD25, CD38, or SEMA7A protein or mRNA expression (Figure S12D).

These data support a mechanism whereby the generation of pyruvate, but not mitochondrial transport and metabolism, is critical for T cell-mediated activation. To further confirm this, we utilized CD4 ${ }^{+} \mathrm{T}$ cells from a conditional MPC1-deficient mouse model (CD4-Cre MPC1 $\left.1^{\mathrm{fl} / \mathrm{fl}}\right)$, that we have recently described [38]. CD4 ${ }^{+} \mathrm{T}$ cells from MPC1 $\mathrm{KO}$ or WT mice were stimulated with anti-CD3/CD28 for 24h. The levels of MPC1 expression were analyzed by qRT-PCR, confirming MPC1 deletion in CD4 ${ }^{+} \mathrm{T}$ cells from CD4-Cre MPC1//fl animals (Figure 4D). Under the same conditions the surface expression of CD25 and CD69, another early activation marker, were evaluated (Figure 4E, S13A-B). Transcription of II2ra and Sema7a were also evaluated by qRT-PCR (Figure 4F, S13C). MPC1-deletion did not affect TCR-mediated 
increases in either transcription or protein expression, demonstrating that mitochondrial pyruvate transport is not required for transcriptional regulation of these genes in in vitro activated $\mathrm{CD}^{+} \mathrm{T}$ cells.

We subsequently evaluated the requirement for mitochondrial pyruvate-transport on CD4 ${ }^{+} \mathrm{T}$ cell function, and the impact of the loss of MPC1 on peripheral T cell responses. To this end, we again utilized the experimental autoimmune encephalomyelitis (EAE) model. Mice lacking MPC1 in T cells have normal evolution of disease compared with WT (Figure 4G). At the endpoint of the experiment, leukocytes were isolated from the brain and spine, and IFN- $\gamma$ and IL-17A production by CD4+ ${ }^{+}$cells was analyzed by flow cytometry (Figure $4 \mathbf{H}-\mathrm{K}$ ). Consistent with disease scores, our results show that the same percentage of IFN- $\gamma$ and IL-17-producing $\mathrm{CD}^{+} \mathrm{T}$ cells infiltrated brains and spine from WT and CD4-Cre MPC1 $1^{\mathrm{fl} / \mathrm{fl}}$ animals. These data further confirm that MPC1-deficient $\mathrm{CD}^{+} \mathrm{T}$ cells are functional and able to migrate to the inflammatory locus and amplify the immune reaction.

Collectively, these data confirm that during $T$ cell activation, glycolytic pyruvate production, but not its subsequent transport into mitochondrial, is essential for the epigenomic remodeling and effector function of $\mathrm{CD} 4^{+} \mathrm{T}$ cells.

\section{TCR-engagement induces PDC nuclear-translocation and histone-association required for epigenome remodeling and transcription}

The pyruvate dehydrogenase complex has been reported to translocate to the nucleus in a heat-shock protein (Hsp70)-dependent manner [33]. To evaluate the relevance of PDC translocation during $T$ cell activation, nuclei were isolated from human $\mathrm{CD}^{+} \mathrm{T}$ cells stimulated with anti-CD3/CD28 for $24 \mathrm{~h}$, in the presence or absence of 2DG. PDC-E1 was detected by immunoblotting and levels in the nucleus were found to increase during activation in a glycolysis-independent manner (Figure S14A-B). To determine whether nuclear transport of PDC-E1 was indeed Hsp70-dependent, human $\mathrm{CD}^{+} \mathrm{T}$ cells were stimulated with antiCD3/CD28 for $24 \mathrm{~h}$, in the presence or absence of KNK437, which results in decreased expression of inducible Hsp70 [39]. KNK437 decreased nuclear levels of PDC-E1 (Figure 5A). To evaluate whether Hsp70 plays a role in TCR-induced transcription, we activated human $\mathrm{CD}^{+} \mathrm{T}$ cells in the presence or absence of KNK437 and measured the cell-surface expression of CD25, CD38, or SEMA7A. Hsp70-inhibition prevented TCR-mediated increases in CD25, CD38, and SEMA7A expression, correlating with reduced nuclear PDC-E1 expression (Figure 5B-C).

The molecular mechanism by which acetyl-CoA is made available for histone acetylation at the level of chromatin is still not well defined. Based on our observations, a potential mechanism could involve direct interaction between PDC subunits and histones, or histone acetyltransferases such as p300. To determine whether the PDC complex may interact with histones or $\mathrm{p300}$, we performed a proximity ligation assay (PLA), enabling the detection of protein-protein interactions in $\mathrm{T}$ cells, as we have previously described [40, 41]. The colocalization of PDC-E1 and p300, or PDC-E1 and H3K27ac was observed in the nucleus, further supporting our Western blot localization data (Figure 5D, Figure S14C). Notably, the association of PDC-E1-p300 and PDC-E1-H3K27ac was dependent on T cell activation, suggesting that PDC shuttles into the nucleus upon antigenic stimulation.

Taken together, these data support a model where the T cell activation results in Hsp70mediated nuclear translocation of PDC and association with chromatin. 


\section{Discussion}

Despite sufficient oxygen being present for the generation of ATP by mitochondrial respiration, when $T$ lymphocytes encounter antigen they undergo metabolic reprograming to exploit aerobic glycolysis [6, 42-44]. What remains unclear is how glycolytic intermediates are specifically utilized during these early stages of $T$ cell activation. Clearly, activation-induced glucose uptake plays important roles in T cell development, proliferation, and function [8, 27, $32,45-48]$. The switch to glycolysis is considered necessary to facilitate carbon incorporation into the biomass that is required during the acute and rapid expansion of $T$ cells upon activation $[11,12]$. However, recent data have challenged this concept showing that carbon biosynthesis from glucose does not contribute to most of the carbon in proliferating murine $T$ lymphocytes [14]. Furthermore, while CD4 ${ }^{+} \mathrm{T}$ cells can use either OXPHOS or glycolysis to fuel proliferation, this can also proceed in the absence of aerobic glycolysis [27]. These and other observations suggest that glycolysis is essential for intracellular processes in addition to generating intracellular building blocks and energy production. Here, we show that activation of CD4 $4^{+} \mathrm{T}$ cells results in epigenetic and transcriptional reprogramming that is dependent on glycolysis to generate extra-mitochondrial pyruvate, with its subsequent metabolism to acetyl-CoA by pyruvate dehydrogenase. This occurs in parallel with the nuclear translocation of pyruvate dehydrogenase, and its subsequent association with histones and histone acetyltransferase (Figure S15A). These observations provide novel insights into the early stages of $\mathrm{CD}^{+} \mathrm{T}$ cell activation, helping to explain why increased glucose uptake is required for $\mathrm{T}$ cell proliferation and development and demonstrating specificity in terms of the metabolic pathways required for these events.

In eukaryotes, acetyl-CoA is produced in the subcellular compartment where it is required [33]. Thus, regulation of nuclear acetyl-CoA production likely serves as a critical step in the regulation of epigenome remodeling [17]. This is supported in studies of Saccharomyces cerevisiae where nuclear acetyl-CoA synthesis is rate-limiting for histone acetylation [49]. Our data show that, during $T$ cell activation, carbons derived from glucose are incorporated into acetylated histones (Figure 1G) providing a direct link between glycolysis and de novo histone acetylation required to remodel the epigenome. Deletion of the glycolytic enzyme lactate dehydrogenase $\mathrm{A}$ (LDHA) in CD4 ${ }^{+} \mathrm{T}$ cells has been shown to inhibit glycolysis, reduce acetylCoA levels, and lower H3K9ac levels at the IFN- $\gamma$ enhancer [19]. However, this study focused on $\mathrm{H} 3 \mathrm{~K} 9 \mathrm{ac}$ and did not explore global transcriptional reprogramming. It also remains unclear how LDHA deficiency directly modulates acetyl-CoA levels. A $30 \%$ reduction in glucose uptake was observed in LDHA knockout animals which could in itself affect H3K9ac through mechanisms we have described here. In contrast, our data demonstrate that activation of $T$ cells in presence of galactose or DCA [27], inhibiting the conversion of pyruvate to lactate, does not affect H3K27ac levels or transcription during T cell activation (Figure 1E 4A-C, S12AC). This suggests that inhibition of lactate production does not impact H3K27ac enhancer remodeling after TCR engagement. However, inhibiting the conversion of glucose to pyruvate by 2DG or 3PO abrogated H3K27 acetylation without affecting histone acetyltransferase expression (data not show).

While acetyl-CoA can be produced from acetate, citrate, or pyruvate, how this is regulated, or whether specificity is important during the early phase of $T$ cell activation, remain important and currently unanswered questions. We show that blocking mitochondrial pyruvate transport, or inhibiting ACLY and ACSS2, did not affect activation-induced H3K27ac or transcription (Figure 2A-M, 4D-F). We have also shown that inhibition of mitochondrial pyruvate transport abrogates $T$ cell activation-induced OXPHOS and reduced citrate levels (Figure S11C and reference [38]). This supports the concept that neither citrate, acetate, nor mitochondrial 
intermediate metabolites are required for epigenetic remodeling. Instead, our data support a model whereby extra-mitochondrial pyruvate-synthesis is crucial for epigenome remodeling, rather than TCA cycle intermediary products. This is supported by a recent study by Menk et al in which it was shown that upregulation of pyruvate dehydrogenase kinase 1 (PDHK1) activity, preventing mitochondrial import of pyruvate, is acutely required for $\mathrm{T}$ cell activationinduced cytokine synthesis [50]. T cells have been recently reported to utilize acetate to remodel the epigenome, in an acetyl-CoA synthetase (ACSS)-dependent manner, but this was specifically under conditions of glucose restriction and activating the T cells during 5 or 9 days [21]. Our data also show that in presence of glucose, ACSS2 inhibition does not affect transcriptome remodeling during T cell activation (Figure 2 B-C). Additionally, the provision of exogenous acetate during $T$ cells activation was not sufficient to rescue epigenome remodeling when glycolysis was inhibited (Figure 2D). A role for mitochondrial metabolism and polyamine metabolism have also been described to regulate epigenetic changes during the differentiation of $\mathrm{CD}^{+} \mathrm{T}$ cells into $\mathrm{T}$ helper cell subsets $[20,22]$. However, these studies examined murine lymphocytes several days after activation-induced differentiation. Taking our data into account, it further highlights the large degree of flexibility exhibited by $\mathrm{CD}^{+} \mathrm{T}$ cells in exploiting metabolic changes to drive chromatin remodeling.

Pyruvate dehydrogenase has recently been shown to play a role in thymic maturation of $T$ cells [31] and it was proposed that it doesn't have a role in T cell numbers downstream of the doublepositive stage of differentiation. We observed a small but significant change in the quantity of $\mathrm{CD}^{+} \mathrm{T}$ cells in the spleen in our inducible knockout model (Figure $3 \mathrm{H}$ ). However, during the first $24 \mathrm{~h}$ of after TCR-engagement, PDC is required for transcriptional reprogramming (Figure 3I-N), and this is essential for T cell activation in vitro and in vivo (Figure 30). Mitochondrial pyruvate dehydrogenase complex (PDC) has previously been reported to be present and functional in the nucleus of fibroblasts. Knockdown of nuclear PDC components in isolated functional nuclei decreased the de novo synthesis of acetyl-CoA and acetylation of core histones [33]. Our data demonstrate that in T cells, PDC-E1, a subunit of the PDC complex, is translocated to the nucleus in an Hsp70-dependent manner during CD4 ${ }^{+} \mathrm{T}$ cell activation (Figure 5A). Inhibition of nuclear translocation or depletion of PDC-E1 prevented activationinduced changes in $\mathrm{CD}^{+}{ }^{+} \mathrm{T}$ cell transcription (Figure $\mathbf{3 K}-\mathbf{N}, 5 \mathrm{~B}-\mathrm{C}$ ). Furthermore, we demonstrate that PDC is in close proximity to both H3K27ac and the p300 acetyltransferase upon $\mathrm{T}$ cell activation, and by this mechanism could maintain higher local acetyl-CoA concentrations at specific enhancers and promotors. This association between PDC, histones, and p300 is also regulated in a TCR-activation-dependent manner and may be critical in directing the rapid changes in enhancer-activation and transcription observed in $\mathrm{CD}^{+} \mathrm{T}$ cells after initial TCR-engagement (Figure 5D).

Our data demonstrate clear specificity in the use of intermediate metabolites in the generation of acetyl-CoA, chromatin remodeling, and transcriptional reprogramming after $\mathrm{CD}^{+} \mathrm{T}$ cell activation. Furthermore, the association of PDC subunits with histones and histone acetyltransferases suggests a potentially deterministic role in driving the specificity of enhancer activation. The tight integration of metabolic enzymes with histones, and chromatin-modifying enzymes allows metabolic reprogramming to fuel acute and rapid changes in transcriptional output. While our data has focused on the early stages of $C D 4^{+} \mathrm{T}$ cell activation, these findings could be applicable to a variety of systems where metabolism drives changes in cell fate. 


\section{Figure Legends}

Figure 1. Glycolytic reprogramming is essential for TCR-induced epigenome remodeling and transcription. (A) Immunoblots of H3AcK27, H3K27me3, H3K4me3, $\mathrm{H} 3 \mathrm{~K} 4 \mathrm{me} 1$, and $\mathrm{H} 3$ global levels in human PB CD4 ${ }^{+} \mathrm{T}$ cells activated with anti-CD3/CD28 in the presence or absence of either oligomycin, 2DG, or Galactose for 20h. (B) Principle component analysis based on H3K27ac signal in enhancers. (C-E) MA plots of H3K27ac signal at enhancers, based on comparisons of all replicates within the depicted groups. Red dots indicate enhancers with an FDR $<0.05$. (F) CD4+ T cells were activated for $24 \mathrm{~h}$ with antiCD3/CD28 antibodies in the absence or presence of oligomycin or 2DG, and levels of acetylCoA were measured. (G) LC-MS/MS analysis of the relative levels of isotopically labeled acetylated H3K27Ac (K(Ac)SAPSTGGVK) peptide from resting or stimulated $T$ cells in absence or presence of 2-deoxyglucose (2-DG), 24h after stimulation and resuspension in medium containing $11 \mathrm{mM}$ [U- $\left.{ }^{13} \mathrm{C}\right] \mathrm{D}-$ Glucose. $\mathrm{M}+2 / \mathrm{M} 0$ indicates the ratio ${ }^{13} \mathrm{C}_{2}$ labeled peptide/monoisotopic peptide, $\mathrm{M}+3 / \mathrm{M}+1$ indicates the ratio in case of one additional ${ }^{13} \mathrm{C}$ isotope, which serves as a technical replicate. Indicated is the expected ratio based on the natural abundance of ${ }^{13} \mathrm{C}$. Data are shown as mean $\pm \mathrm{SD}$ of triplicate samples. ${ }^{*} \mathrm{P}<0.05$; ${ }^{* *} \mathrm{P}<0.01 ;{ }^{* * *} \mathrm{P}<0.001$ (ANOVA).

Figure 2. ACSS2 inhibition or the absence of ACLY doesn't affect the epigenome remodeling induced during $\mathbf{T}$ cell activation. (A) Immunoblots of ACLY, ACSS2, PDCE1, and Actin from human $T$ cells activated for $8,16,24$, or $48 \mathrm{~h}$ with anti-CD3/CD28. (B-C) CD25 protein expression was measured by FACS and IL2ra by qRT-PCR in human CD4+ ${ }^{+}$cells activated with anti-CD3/CD28 in the absence or presence of acyl-coenzyme A synthetase short-chain family member 2 (ACSS2 [15.6uM]) inhibitor. (D) CD25, expression was measured by qRT-PCR in human $C D 4^{+} \mathrm{T}$ cells activated with anti-CD3/CD28 in the absence or presence of $2 D G$ or $2 D G$ with Acetate $(20 \mathrm{mM})$. (E-F) CD25 protein expression was measured by flow cytometry (FACS) and IL2ra by qPCR in human CD4 ${ }^{+}$T cells activated with anti-CD3/CD28 in the absence or presence of two ATP citrate lyase (ACLY) inhibitors (SB204990 [5uM] and BMS303141 [30uM]). (G) Gene expression of $A C L Y$ by naïve murine CD4 ${ }^{+} \mathrm{T}$ cells 24 hours after in vitro activation with $\alpha C D 3 / \alpha C D 28$ as measured by qRT-PCR. (H) Percentage of CD25 on naïve murine CD4 ${ }^{+} T$ cells 24 hours after in vitro activation with $\alpha C D 3$ and $\alpha C D 28$. (I) Gene expression of II2ra by naïve murine $\mathrm{CD}^{+} \mathrm{T}$ cells 24 hours after in vitro activation with aCD3/aCD28 as measured by qRT-PCR. (J) MA plots of differentially expressed genes, based on comparisons of all replicates within the depicted groups. Red dots indicate enhancers with an FDR $<0.1$. (K) Gene set enrichment analysis between upregulated T cell activation gene set and different expression genes between WT and ACLY-Ko activated T cells. (L) Gene set enrichment analysis between $T$ cell activation regulated by glycolysis gene set and different expression genes between WT and ACLY-KO activated T cells. Data are shown as mean \pm $\mathrm{SD}$ of triplicate samples. ${ }^{*} \mathrm{P}<0.05 ;{ }^{* *} \mathrm{P}<0.01 ;{ }^{* *} \mathrm{P}<0.001$ (ANOVA or $\mathrm{T}$ test).

Figure 3. Production of intracellular pyruvate through glycolysis and the conversion of this Pyruvate to AcCoA by PDC is required for remodeling of the epigenome landscape. Intracellular ${ }^{13} \mathrm{C}$-labelled pyruvate analysis by LC-MS of stimulated $\mathrm{T}$ cells in absence or presence of 2-deoxyglucose (2-DG) at 3,6,16, and 24h after stimulation. On cells that were suspended in MEDIUM containing $11 \mathrm{mM}\left[\mathrm{U}-{ }^{13} \mathrm{C}\right]-D-G l u c o s e .(B)$ Chip-qPCR of IL2RA enhancer regions from human $\mathrm{CD}^{+} \mathrm{T}$ cells activated with anti-CD3/CD28 antibodies in the absence or presence of 2DG, or 2DG with pyruvate (2mM). (C) ChIP-qPCR of IL2RA enhancer region from human $C D 4^{+} T$ cells activated with anti-CD3/CD28 in the absence or presence of 6,8-Bis(benzylthio) octanoic acid (PDC Inhibitor) or PDC Inhibitor with pyruvate (2mM). (D) CD25 expression was measured by flow cytometry in human CD4 ${ }^{+} \mathrm{T}$ cells activated with anti- 
CD3/CD28 in the absence or presence of 6,8-Bis(benzylthio) octanoic acid (PDC-inhibitor) or PDC-inhibitor with pyruvate. (E-F) mRNA expression of PDHA1 and IL2RA measured by qRTPCR on Human CD4+ T transfected with siRNA PDHA1 or siRNA Control and activated 24 hours. (G) Representative photos of spleens from wild-type (WT) and PDHA1 deficient mice. The relative weight of spleen of $\mathrm{Wt}$ and PDHA1 deficient mice. $(\mathrm{H}) \mathrm{CD} 4$ and CD8 cells subpopulations of the spleens from PDHA1 deficient mice and CD4CreERT2 littermate controls were analyzed by flow cytometry at 6 weeks old. (I) Mean fluorescence intensities of CD25 on naïve murine CD4+ T cells 24 hours after in vitro activation with aCD3 and $\alpha C D 28$. Data is representative of multiple experiments. $(\mathbf{J})$ Gene expression of II2ra by naïve murine CD4 ${ }^{+} \mathrm{T}$ cells 24 hours after in vitro activation with $\alpha C D 3 / \alpha C D 28$ as measured by qRT-PCR. (K) MA plots of differentially expressed genes, based on comparisons of all replicates between Activated Wt T cell and activated PDHA1 deficient mice T cells. Red dots indicate enhancers with an FDR $<0.1$. (L) Gene set enrichment analysis between upregulated $T$ cell activation gene set and different expression genes between $\mathrm{Wt}$ and PDHA1 deficient activated T cells. (M) Gene set enrichment analysis between T cell activation regulated by glycolysis gene set and different expression genes between $\mathrm{Wt}$ and PDHA1 deficient activated T cells. (N) Heatmap of activation genes with differential expression between activated PDHA1-deficient or $A C L Y$-deficient $C D 4^{+} \mathrm{T}$ cells, and cells activated Wt CD4 ${ }^{+} \mathrm{T}$ cells. $(\mathbf{O})$ Clinical scores of mice induced with EAE (CD4 ${ }^{\text {CreERT2 }}$ PDHA1 fl/fl, $\mathrm{n}=16$; ${ }^{\mathrm{CD}} 4^{\mathrm{CreERT}}, \mathrm{n}=9$ ) from two separate experiments. All graphs represent mean $+/-S D$. Statistical significance was measured by Oneway ANOVA, Student's T-test, or Mann-Whitney test of the area under the curve for EAE clinical score. ${ }^{*} \mathrm{P}<0.05 ;{ }^{* \star} \mathrm{P}<0.01 ;{ }^{* \star *} \mathrm{P}<0.001$.

Figure 4. The T cell's incapacity to introduce pyruvate from glycolysis on the mitochondria for the absence of MPC1 doesn't impact the epigenome remodeling.

(A) ChIP-qPCR of IL2RA enhancer region from human CD4 ${ }^{+} \mathrm{T}$ cells activated with antiCD3/CD28 in the absence or presence of 2DG, 3PO, UK5099, or DCA. (B) IL2RA mRNA expression was measured by qRT-PCR in human $\mathrm{CD}^{+}{ }^{+} \mathrm{T}$ cells activated with anti-CD3/CD28 in the absence or presence of 2DG, 3PO, UK5099, or DCA. (C) CD25 protein expression was measured by FACS in human CD4 ${ }^{+} \mathrm{T}$ cells activated with anti-CD3/CD28 in the absence or presence of 2DG, 3PO, UK5099, or DCA. (D) Gene expression of Mpc1 by naïve murine CD4+ T cells 24 hours after in vitro activation with $\alpha C D 3 / \alpha C D 28$ as measured by qRT-PCR. (E) Mean fluorescence intensities of CD25 on naïve murine CD4+ T cells 24 hours after in vitro activation with $\mathrm{\alpha CD} 3$ and $\mathrm{\alpha CD} 28$. Data is representative of multiple experiments. (F) Gene expression of II2ra by naïve murine CD4 ${ }^{+} \mathrm{T}$ cells 24 hours after in vitro activation with $\alpha \mathrm{CD} 3 / \alpha \mathrm{CD} 28$ as measured by qRT-PCR. (G) Clinical scores during EAE. Data represent $n=14$ mice/group from two separate experiments. $(\mathbf{H}-\mathbf{I})$ Percent of $\mathrm{CD}^{+} \mathrm{T}$ cells in the brains of EAE mice expressing IL-17A and IFN $\gamma$ measured by flow cytometry at day 20. (J-K) Percent of CD4 ${ }^{+} \mathrm{T}$ cells in the spines of EAE mice expressing IL-17A and IFN $\gamma$ measured by flow cytometry at day 20. All graphs represent mean $+/-S D$. Statistical significance was measured by One-way ANOVA or Student's T-test. ${ }^{*} \mathrm{P}<0.05 ;{ }^{* \star} \mathrm{P}<0.01 ;{ }^{* *} \mathrm{P}<0.001$.

Figure 5. Nuclear translocation of PDC by TCR engagement is required for remodeling of the epigenome landscape. (A) Immunoblots showing that PDCE1 localization in the nucleus of $\mathrm{HC}$ CD4+ T cells activated with anti-CD3/CD28 in the absence or presence of KNK437 (Hsp70 inhibitor). Graph bars show the mean + SD of quantifications of immunoblots from five different experiments. (B-C) CD25, CD38, and SEMA7A expression were measured by flow cytometry (FACS) and qRT-PCR in human $\mathrm{CD}^{+} \mathrm{T}$ cells activated with anti-CD3/CD28 in the absence or presence of KNK437 (Hsp70 inhibitor). (D) PLA analysis of PDCE1:H3K27ac or PDCE1:p300 association in resting human CD4+ T cells and cells activated with antiCD3/CD28 for $24 \mathrm{~h}$. All graphs represent mean $+/-$ SD. Statistical significance was measured by One-way ANOVA or Student's T-test. ${ }^{*} \mathrm{P}<0.05 ;{ }^{* *} \mathrm{P}<0.01 ;{ }^{* *} \mathrm{P}<0.001$. 


\section{Supplementary Figure Legends}

Supplementary Figure 1. (A) Immunoblots of H3AcK27, H3K27me3, H3K4me3, H3K4me1, and $\mathrm{H} 3$ from human $\mathrm{T}$ cells activated for 8,12 , or $24 \mathrm{~h}$ with anti-CD3/CD28. (B) Graph bars show the mean $+\mathrm{SD}$ of quantifications of immunoblots from three different experiments.

Supplementary Figure 2. (A) MA plots of genes differentially expressed between resting and activated (CD3/CD28 24h) HC PB CD4+ T cells. Red dots indicate genes with an FDR $<0.05$. (B) Gene ontology terms, ranked by enrichment scores of genes that are up-regulated on activated versus resting CD4 ${ }^{+}$T cells. (C) MA plots of H3K27ac signal at enhancers, based on comparisons of Resting vs Activated (CD3/CD28 24h) HC PB CD4+ T cells. Red dots indicate genes with an FDR $<0.01$. (D) Gene ontology terms, ranked by enrichment scores of enhancers (Es) that are up-regulated on activated versus resting CD4+ $T$ cells. (E) Venn diagram of all enhancers (Es) and genes that were up-regulated on activated versus resting $\mathrm{CD}^{+} \mathrm{T}$ cells. (F) Gene ontology terms for biological processes (ranked on enrichment score) of genes that overlap between ChIP-seq and RNA-seq data in (E). (G) Gene set enrichment analysis between gene set enrichment analysis and H3K27ac signal.

Supplementary Figure 3. (A) Heatmap of metabolic genes with significant differential expression between resting human $\mathrm{CD} 4^{+} \mathrm{T}$ cells, and cells activated with anti-CD3/CD28 for 24h. (B) H3K27ac levels in the promoter region (+/- 2.5kb) of metabolic genes.

Supplementary Figure 4. (A) Graph bars show mean + SD of quantifications of immunoblots from three different experiments. (B-D) MA plots of differentially expressed genes, based on comparisons of all replicates within the depicted groups. Red dots indicate enhancers with an FDR $<0.05$. (E) Principle component analysis based on $\mathrm{CD} 4^{+} \mathrm{T}$ cell genes with significant differential expression between resting and CD3/CD28 activated for 24h, and in the absence or presence of either oligomycin, 2DG, or replacing glucose for galactose. (F) Venn diagram of all enhancers (Es) and genes up-regulated significantly inactivated versus resting $\mathrm{CD}^{+} \mathrm{T}$ cells in the presence or absence of 2DG.

Supplementary Figure 5. (A) Gene ontology terms for biological processes (ranked on enrichment score) of CD4+ T cell activation genes that were inhibited by 2DG-treatment. (B) Selected CD4+ T cell activation genes whose expression was inhibited by 2DG-treatment. (C) $\mathrm{CD}^{+} \mathrm{T}$ cells gene tracks for IL2RA, SEMA7A and CD38 showing H3K27C ChIP-seq signals from resting, activated (anti-CD3/CD28, 20h) or activated with 2DG-treatment. Each lightgreen-shaded area represents an individual Enhancer.

Supplementary Figure 6: (A) IL2-RA (CD25), SEMA7A, and CD38 surface expression was monitored by flow cytometry from sorted CD4+ T cells after activation for 24h with CD3/CD28 (representative, $\mathrm{n}=3$ ). (B) mRNA expression of IL2RA, CD38, and SEMA7A was measured by qRT-PCR in human $C D 4^{+} T$ cells activated with anti-CD3/CD28 in the presence of $2 D G$ or absence of Glucose. (C) CD25, CD38, and SEMA7A protein expression was measured by flow cytometry (FACS) in human CD4 ${ }^{+} \mathrm{T}$ cells activated with anti-CD3/CD28 in the presence of 2DG or absence of Glucose. (D) Extracted ion chromatograms from LC-MS/MS analysis of the acetylated Histone H3K27Ac peptide (K(Ac)SAPSTGGVK) from resting or stimulated T cells in absence or presence of 2-deoxyglucose (2-DG), 24h after stimulation and resuspension in medium containing $11 \mathrm{mM}\left[\mathrm{U}-{ }^{13} \mathrm{C}\right] \mathrm{D}$-Glucose. All graphs represent mean $+/-\mathrm{SD}$. Statistical significance was measured by One-way ANOVA or Student's T-test. ${ }^{*} \mathrm{P}<0.05$; ${ }^{*} \mathrm{P}<0.01$; ${ }^{* * *} \mathrm{P}<0.001$. 
Supplementary Figure 7: (A) Graph bars show mean + SD of quantifications of immunoblots from four different experiments. All graphs represent mean +/- SD. Statistical significance was measured by One-way ANOVA or Student's T-test. ${ }^{*} \mathrm{P}<0.05$; ${ }^{* *} \mathrm{P}<0.01 ;{ }^{* * *} \mathrm{P}<0.001$.

Supplementary Figure 8: (A-B) CD38 and SEMA7A protein expression was measured by FACS and qRT-PCR in human CD4 ${ }^{+}$T cells activated with anti-CD3/CD28 in the absence or presence of two ATP citrate lyase (ACLY) inhibitors (SB204990 and BMS303141). (C) Principle component analysis based on naïve murine CD4+ T cells isolated from WT or ACLY Ko mice genes with significant differential expression between resting and CD3/CD28 activated for $24 \mathrm{~h}$. All graphs represent mean $+/-$ SD. Statistical significance was measured by One-way ANOVA or Student's T-test. ${ }^{*} \mathrm{P}<0.05$; ${ }^{* *} \mathrm{P}<0.01$; ${ }^{* *} \mathrm{P}<0.001$.

Supplementary Figure 9: (A) Chip-qPCR of CD38 and SEMA7A enhancer regions from human $\mathrm{CD}^{+} \mathrm{T}$ cells activated with anti-CD3/CD28 antibodies in the absence or presence of 2DG or 2DG with pyruvate (2mM). (B) ChIP-qPCR of CD38 and SEMA7A enhancer regions from human $\mathrm{CD}^{+} \mathrm{T}$ cells activated with anti-CD3/CD28 in the absence or presence of 6,8Bis(benzylthio) octanoic acid (PDC Inhibitor) or PDC Inhibitor with pyruvate (2mM). (C) Expression of CD38 and Semaphorin 7A (SEMA7A) were measured by flow cytometry in human $\mathrm{CD}^{+} \mathrm{T}$ cells activated with anti-CD3/CD28 in the absence or presence of 6,8Bis(benzylthio) octanoic acid (PDC-inhibitor) or PDC-inhibitor with pyruvate (2mM). (D) mRNA expression of $C D 38$ and SEMA7A measured by qRT-PCR on Human CD4+ T transfected with siRNA PDHA1 or siRNA Control and activated 24 hours. All graphs represent mean +/- SD. Statistical significance was measured by One-way ANOVA or Student's T-test. ${ }^{*} \mathrm{P}<0.05$; ${ }^{* *} \mathrm{P}<0.01 ;{ }^{* *} \mathrm{P}<0.001$

Supplementary Figure 10: (A) Gene expression of $P D H A 1$ by $\mathrm{CD}^{+} \mathrm{T}$ cells isolated from $\mathrm{Wt}$ or PDHA1 deficient mice. (B) Immunoblots and Wb quantification of PDCE1, PDCE2, and Actin in murine $\mathrm{CD}^{+} \mathrm{T}$ cells from Wt or PDHA1 deficient mice. (C) CD45, CD45RB, CD11B, and CD128 cells subpopulations of the spleens from PDHA1 deficient mice mice and CD4 ${ }^{\text {CreERT2 }}$ littermate controls were analyzed by flow cytometry at 6 weeks old. (D-G) CD4 ${ }^{+}$isolated from Wt or PDHA1 deficient mice were treated with anti-CD3/CD28 antibodies for 24h and Oxygen Consumption Rate (OCR) and ExtraCellular Acidification Rate (ECAR) were measured by Seahorse technology. All graphs represent mean $+/-$ SD. Statistical significance was measured by One-way ANOVA or Student's T-test. ${ }^{*} \mathrm{P}<0.05$; ${ }^{* *} \mathrm{P}<0.01 ;{ }^{* * *} \mathrm{P}<0.001$.

Supplementary Figure 11: (A) Schematic showing the metabolic enzyme targets for drugs used in our experiments in the glycolysis and TCA-cycle pathways. (B-C) Oxygen Consumption Rate (OCR) and ExtraCellular Acidification Rate (ECAR) in human CD4 ${ }^{+} \mathrm{T}$ cells activated with anti-CD3/CD28 in the absence or presence of glycolysis inhibitors (2DG and 3PO), 2-Cyano-3-(1-phenyl-1H-indol-3-yl)-2-propenoic acid (UK5099) pyruvate transporter inhibitor, mitochondrial respiration inhibitor (Oligomycin), PDK-inhibitor (DCA), glucosegalactose replacement, or 6,8-Bis(benzylthio)octanoic acid (PDC-inhibitor). (D-F) CD4+ ${ }^{+}$cell viability was measured using flow cytometry with annexin $V$ staining, or by counting Trypan Blue-positive cells in the absence or presence of inhibitor treatment as indicated. All graphs represent mean +/- SD. Statistical significance was measured by One-way ANOVA or Student's T-test. ${ }^{\star} \mathrm{P}<0.05 ;{ }^{* *} \mathrm{P}<0.01 ;{ }^{* *} \mathrm{P}<0.001$.

Supplementary Figure 12: (A) ChIP-qPCR of CD38 and SEMA7A enhancer regions from human $C D 4^{+} T$ cells activated with anti-CD3/CD28 in the absence or presence of 2DG, 3PO, UK5099, or DCA. (B) mRNA expression of CD38 and SEMA7A was measured by qRT-PCR in human $\mathrm{CD}^{+} \mathrm{T}$ cells activated with anti-CD3/CD28 in the absence or presence of 2DG, 3PO, 
UK5099, or DCA. (C) CD38 and SEMA7A protein expression was measured by flow cytometry (FACS) in human CD4 $4^{+}$cells activated with anti-CD3/CD28 in the absence or presence of 2DG, 3PO, UK5099, or DCA. (D) CD25, CD38, and Sema7 protein expression were measured by FACS and $C D 25, C D 38$, and SEMA7 by qRT-PCR in human $C D 4^{+} \mathrm{T}$ cells activated with anti-CD3/CD28 in the absence or presence of MPC2 (Rosiglitazone [50uM]) inhibitor. All graphs represent mean $+/$ - SD. Statistical significance was measured by One-way ANOVA or Student's T-test. ${ }^{*} \mathrm{P}<0.05 ;{ }^{* *} \mathrm{P}<0.01 ;{ }^{* *} \mathrm{P}<0.001$.

Supplementary Figure 13: (A) Representative plots of CD69 and CD25 expression on WT and MPC1-deficient naïve murine $\mathrm{CD}^{+}{ }^{+} \mathrm{T}$ cells 24 hours after in vitro activation with aCD3/aCD28. (B) Mean fluorescence intensities of CD69 on naïve murine CD4+ $T$ cells 24 hours after in vitro activation with $\alpha \mathrm{CD} 3 / \mathrm{\alpha CD} 28$. Data is representative of multiple experiments. (C) Gene expression of Sema7a by naïve murine CD4 ${ }^{+} \mathrm{T}$ cells 24 hours after in vitro activation with $\mathrm{aCD} 3 / \mathrm{aCD} 28$ as measured by qRT-PCR. All graphs represent mean +/- SD. Statistical significance was measured by One-way ANOVA or Student's T-test. ${ }^{*} \mathrm{P}<0.05$; ${ }^{* *} \mathrm{P}<0.01$; ${ }^{* * *} \mathrm{P}<0.001$

Supplementary Figure 14: (A) Immunoblots showing that PDCE1 localization in the nucleus of $\mathrm{HC} \mathrm{CD4+} \mathrm{T}$ cells activated with anti-CD3/CD28 in the absence or presence of 2DG. (B) Graph bars show the mean + SD of quantifications of immunoblots from five different experiments. (C) PLA negative control of PDCE1, H3K27ac, or P300 in human CD4+ T cells activated with anti-CD3/CD28 for 24h. All graphs represent mean +/- SD. Statistical significance was measured by One-way ANOVA or Student's T-test. ${ }^{*} \mathrm{P}<0.05$; ${ }^{*} \mathrm{P}<0.01$; ${ }^{* * *} \mathrm{P}<0.001$.

Supplementary Figure 15: (A) Schematic model depicting the role of extra-mitochondrial pyruvate metabolism and PDC translocation in regulating $\mathrm{CD}^{+}{ }^{+} \mathrm{T}$ cell transcription. 


\section{Materials and Methods}

\section{Collection of PB Samples.}

Peripheral blood (PB) was obtained from healthy donors (Hc) under the Minidonor Din Program (UMC Hospital). PB was drawn at the same moment via vein puncture or intravenous drip. The study procedures were approved by the Institutional Review Board of the University Medical Center Utrecht (UMCU; METC nr: 11-499c) and performed according to the principles expressed in the Helsinki Declaration. Peripheral blood mononuclear cells (PBMCs) were isolated using Ficoll Isopaque density gradient centrifugation (GE Healthcare Bio-Sciences $\mathrm{AB}$ ) and were used fresh or after freezing in FCS (Invitrogen) containing 10\% DMSO (SigmaAldrich).

\section{Human $\mathrm{T}$ cell isolation and culture}

$\mathrm{CD}^{+} \mathrm{T}$ cells were isolated from PBMCs using MagniSortTM Human CD4 ${ }^{+} \mathrm{T}$ cell Enrichment Kit (eBioscience 8804-6811-74). The CD4 ${ }^{+} \mathrm{T}$ cells were cultured always in RPMI Medium 1640 + GlutaMAX supplemented with $100 \mathrm{U} / \mathrm{ml}$ penicillin, $100 \mathrm{mg} / \mathrm{ml}$ streptomycin (all obtained from Life Technologies), and 10\% heat-inactivated human AB-positive serum (Invitrogen) at 37\% $\mathrm{C}$ in $5 \% \mathrm{CO} 2$. Where indicated, CD4 ${ }^{+} \mathrm{T}$ cells were activated with $1 \mu \mathrm{g} / \mathrm{ml}$ plate-bound anti-CD3 (eBioscience; 16-0037) and $1 \mu \mathrm{g} / \mathrm{ml}$ anti-CD28 (eBioscience; 16-0289-85) during 12, 24 or 48 hours. Where indicated cells were treated with Oligomycin (1 $\mu \mathrm{M}$ Sigma Aldrich), 2DG $(50 \mathrm{mM}$

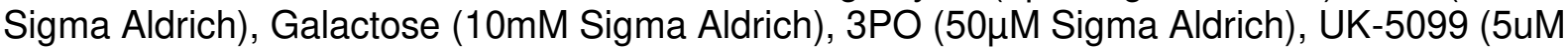
Sigma Aldrich), DCA (5mM Tocris Bioscience), Etomoxir (3uM, 5uM, and 10uM Sigma Aldrich), SB204990 (Med Chem Express), BMS303141 (Sigma Aldrich), ACSS2-Inhibitor (15uM Selleck) 6,8-Bis(benzylthio) octanoic acid (Sigma Aldrich), Na-pyruvate $2 \mathrm{mM}$ or Acetate (20mM).

\section{Chromatin-immunoprecipitation}

For each sample, cells were crosslinked with $2 \%$ formaldehyde and crosslinking was stopped by adding $0.2 \mathrm{M}$ glycine. Nuclei were isolated in $50 \mathrm{mM}$ Tris (pH 7.5), $150 \mathrm{mM} \mathrm{NaCl}, 5 \mathrm{mM}$ EDTA, 0.5\% NP-40, and 1\% Triton X-100 and lysed in $20 \mathrm{mM}$ Tris (pH 7.5), $150 \mathrm{mM} \mathrm{NaCl}, 2$ mM EDTA, $1 \%$ NP-40, $0.3 \%$ SDS. Lysates were sheared using Covaris microTUBE (duty cycle $20 \%$, intensity 3, 200 cycles per burst, 60 -s cycle time, eight cycles) and diluted in $20 \mathrm{mM}$ Tris (pH 8.0), $150 \mathrm{mM} \mathrm{NaCl}, 2 \mathrm{mM}$ EDTA, $1 \% \mathrm{X}-100$. Sheared DNA was incubated overnight with anti-histone H3 acetyl K27 antibody (ab4729; Abcam) pre-coupled to protein A/G magnetic beads. Beads were washed and crosslinking was reversed by adding $1 \%$ SDS, $100 \mathrm{mM}$ $\mathrm{NaHCO}, 200 \mathrm{mM} \mathrm{NaCl}$, and $300 \mathrm{mg} / \mathrm{ml}$ proteinase $\mathrm{K}$. DNA was purified using ChIP DNA Clean \& Concentrator kit (Zymo Research). The Chip DNA was used for sequencing or qPCR

\section{DNA/RNA-Sequencing}

End repair, a-tailing, and ligation of sequence adaptors were done using Truseq nano DNA sample preparation kit (Illumina). Samples were PCR amplified, checked for the proper size range, and for the absence of adaptor dimers on a $2 \%$ agarose gel, and barcoded libraries were sequenced 75 bp single-end on Illumina NextSeq500 sequencer (Utrecht DNA sequencing facility). Total cellular RNA was extracted using the RNAeasy kit (QIAGEN). Sample preparation was performed using TruSeq stranded total RNA with ribo-zero globin sample preparation kit (Illumina), and samples were sequenced 75 bp single-end on Illumina NextSeq500 (Utrecht DNA sequencing facility).

\section{ChIP-qPCR}

Real-time PCR was performed with PowerSYBR (Applied Biosystems) using a StepOnePlus Real-Time-PCR system (Applied Biosystems). The expression of each gene was normalized to a negative region. All the primers for the Chip-qPCR they were designed based on or Chipseq: qPCR CHIP negative region: F-GAGCCAGGGTTTCTCTGATTC, RCCTCAGTGATCAGCCCTAAATG; qPCR CHIP hIL2RA: CCTCCTGTAAGAGGTACAGACT, R- GAAAGACACCTCAAACAAGCAC; qPCR CHIP 
hCD38: F- GCTCAATGGATCCCGCAGTA, R-GGATCCTGGCATAAGTCTCTGG; qPCR CHIP hSEMA7A: F- GAACCCACTATGGGACACATC, R-CTTGGGACGCCTTGGAAT.

\section{Detection of apoptosis}

Apoptosis was determined with Annexin V-PE apoptosis detection kit (BD Biosciences). Stained cells were acquired by FACS using an LSRII (Becton Dickinson) and data were analyzed with FlowJo software (Tree Star, Inc). Or counting the cells with Bio-Rad ${ }^{\circledR}$ TC20 Automated cell counter in presence of Trypan blue.

\section{Immunoblotting}

Total cellular lysates were prepared using RIPA buffer (1\% Triton-X 100, $1 \%$ sodium deoxycholate, $0.1 \%$ SDS, $0.15 \mathrm{M} \mathrm{NaCl}, 0.01 \mathrm{M}$ sodium phosphate, $\mathrm{pH} 7.2)$. Membranes were incubated with the following primary antibodies: Total Histone $3(\mathrm{H} 3$, cell signaling; $9715 \mathrm{~S})$, Anti-Histone H3-acetyl K27 (H3AcK27, Abcam; ab4729), Anti-trimethyl-Histone H3 K27 (H3K27met ${ }^{3}$, Millipore; 07-449), Histone H3K4me3 antibody (H3K4met ${ }^{3}$, active motif 39159), Anti-Histone H3 (mono methyl K4) antibody (H3K4met ${ }^{1}$, Abcam; ab176877), Anti-Pyruvate Dehydrogenase E1-alpha subunit antibody (PDH1, Abcam; ab110334), Anti-Actin (Santa Cruz; sc-1616). Anti-ACC2 (ACC2, Abcam; ab66038), ATP-Citrate lyase Ab (ACLY, Cell Signaling;4332), and Anti-Cox-2 (Cayman; 160112).

\section{Real-Time PCR}

RNA was isolated from cells using RNeasy Mini Kit (Qiagen) and cDNA was synthesized using Superscript-III First-Strand Synthesis System (Life Technologies). Real-time PCR was performed with PowerSYBR (Applied Biosystems) using a StepOnePlus Real-Time-PCR system (Applied Biosystems). Expression of each gene was normalized to $\beta 2 \mathrm{M}$. The following primer sets were used: RNA q-PCR $\beta 2 \mathrm{M}$ : F- ATGAGTATGCCTGGCCGTGTGA, RGGCATCTTCAAACCTCCATG; RNA qPCR hIL2RA: F-TTATCATTTCGTGGTGGGGCA, RGGCTTCTCTTCACCTGGAAACT; RNA qPCR hCD38: F- GCTCAATGGATCCCGCAGTA, RGGATCCTGGCATAAGTCTCTGG; RNA qPCR hSEMA7A: F- TGATTGCCGCTGTCGCTC, R-TGTAGTTCTCGCAGTCCGTG. RNA qPCR mACLY: F-TTCGTCAAACAGCACTTCC, RATTTGGCTTCTTGGAGGTG. RNA qPCR mCD38: F-GAGCTTCCAGTAACGCATGT, RGGCCTGTAGTTATCCACGCA. RNA qPCR mSEMA7A: F- CGTGGCAAGGTCTACCACTT, R- GACAGGACCCCTTTGTGGAG. RNA qPCR mIL2RA: F- CCTCCTCCATCCTGATCCCA, R- GCTGGCCACTGCTACCTTAT.

\section{Seahorse assays}

$\mathrm{T}$ cells were stimulated with anti-CD3 and anti-CD28 for 12, 24, and 48 hours. Oxygen consumption rates (OCR) and extracellular acidification rates (ECAR) were measured in XF media (non-buffered RPMl 1640 containing $10 \mathrm{mM}$ glucose, $2 \mathrm{mM} \mathrm{L-glutamine,} \mathrm{and} 1 \mathrm{mM}$ sodium pyruvate) under basal conditions and in response to glucose $30 \mathrm{mM}, 1 \mathrm{uM}$ oligomycin, and 50mM of 2DG, on an XF-24 Extracellular Flux Analyzers (Seahorse Bioscience).

\section{Measurements of Acetyl-CoA Levels}

The intracellular levels of acetyl-CoA were detected by using an Acetyl-CoA Assay Kit (Biovision, Milpitas CA), following the manufacturer's instructions.

Sample Preparation and LC-MS Measurement of glycolytic/TCA cycle intermediates Polar metabolites were extracted from $2 \times 10^{6} \mathrm{~T}$-cells isolated from peripheral blood by adding $500 \mu \mathrm{L}$ ice-cold methanol solution containing internal standards. The cell lysis was performed by using a bullet blender and $0.5 \mathrm{~mm}$ glass beads (NextAdvance, USA) in the sample tube. After cell lysis, the extracts were centrifuged for $10 \mathrm{~min}$ at $17000 \mathrm{xg}$ and $4^{\circ} \mathrm{C}$. The complete supernatant was transferred into a fresh $1.5 \mathrm{~mL}$ tube and evaporated to dryness in a vacuum concentrator (Labconco CentriVap, USA) for $1 \mathrm{~h}$. The dried metabolite pellet was dissolved in $120 \mu \mathrm{L}$ of water/acetonitrile solution $(95 \% / 5 \%, \mathrm{v} / \mathrm{v})$ before transferring the material into $\mathrm{LC}$ glass vials. 
The chromatographic separation was performed using a Thermo Fischer Accela UHPLC System equipped with a Waters Acquity C8 column $(2.1 \times 150 \mathrm{~mm}, 1.8 \mu \mathrm{m})$ the outlet of which was connected to an LTQ-Orbitrap XL MS System (ThermoFisher Scientific, USA, and Waters, USA). The LC flow rate was set to $150 \mu \mathrm{L} / \mathrm{min}$ and the column oven temperature was adjusted to $35^{\circ} \mathrm{C}$. Five microliters of the sample were injected on the column. The weak and the strong eluents were $100 \%$ Milli-Q water and methanol/Milli-Q water $(95 \% / 5 \%$, v/v) respectively and both solvents contain $6.5 \mathrm{mM}$ ammonium bicarbonate at $\mathrm{pH} 8.0$. The strong eluent starts at $0 \%$ for $1 \mathrm{~min}$ and increases over $1-5 \mathrm{~min}$ from $0 \%$ to $70 \%$ and from $70 \%$ to $98 \%$ between $5-5.5 \mathrm{~min}$ following an isocratic run over $5.5-15.5 \mathrm{~min}$ and a drop back to the initial $0 \%$ composition between 15.5-22min. The MS data were acquired in full scan mode between 55-900 amu. The peak picking and integration were performed with Thermo Xcalibur Software (v2.4). The target metabolites were identified by running authenticated standards in parallel and comparing their retention time and $\mathrm{m} / \mathrm{z}$ values. The obtained peak areas were corrected by the peak area of the corresponding internal standard.

\section{Liquid chromatography-Mass Spectrometry (LC-MS) based metabolomics}

T cells were seeded at a density of $1 * 10^{6} \mathrm{cells} / \mathrm{ml}$ in RPMI (10\% FBS) by supplemented with $11 \mathrm{mM}\left[\mathrm{U}-{ }^{13} \mathrm{C}\right] \mathrm{D}-\mathrm{Glucose}$ (Cambridge Isotopes). T cells were stimulated in the presence or absence of 2-DG. After 3, 6, 16, 24 hours, $5^{\star} 10^{5}$ cells were harvested, centrifuged for 5 min 1000xG, and the cell pellet was washed with ice-cold PBS. Metabolites were extracted by adding $50 \mu \mathrm{l}$ ice-cold MS lysis buffer (methanol/acetonitrile/ULC/MS grade water (2:2:1)) to the cell pellet. Samples were shaken for 10 minutes at $4^{\circ} \mathrm{C}$, centrifuged at $14.000 \mathrm{~g}$ for $15 \mathrm{~min}$ at $4^{\circ} \mathrm{C}$, and supernatants were collected for LC-MS analysis. LC-MS analysis was performed on an Exactive mass spectrometer (Thermo Scientific) coupled to a Dionex Ultimate 3000 autosampler and pump (Thermo Scientific). The MS operated in polarity-switching mode with spray voltages of $4.5 \mathrm{kV}$ and $-3.5 \mathrm{kV}$. Metabolites were separated using a Sequant ZIC-pHILIC column $(2.1 \times 150 \mathrm{~mm}, 5 \mu \mathrm{m}$, guard column $2.1 \times 20 \mathrm{~mm}, 5 \mu \mathrm{m}$; Merck) using a linear gradient of acetonitrile and eluent $\mathrm{A}(20 \mathrm{mM}(\mathrm{NH} 4) 2 \mathrm{CO}, 0.1 \% \mathrm{NH} 4 \mathrm{OH}$ in ULC/MS grade water (Biosolve)). The flow rate was set at $150 \mu \mathrm{l} / \mathrm{min}$. Metabolites were identified and quantified using LCquan software (Thermo Scientific) based on exact mass within $5 \mathrm{ppm}$ and further validated by concordance with retention times of standards.

\section{Liquid chromatography-Mass Spectrometry (LC-MS) based proteomics}

Bands corresponding to the MW of histones were excised from the polyacrylamide gel, after which they were destained with $50 \%$ Acetonitrile (ACN). After reduction with $10 \mathrm{mM}$ Tris (2carboxyethyl)phosphine hydrochloride (TCEP) in $50 \mathrm{mM}$ Ammonium Bicarbonate (ABC), proteins were alkylated in the dark with $40 \mathrm{mM}$ Chloro-Acetamide. After digestion with $200 \mathrm{ng}$ Tryp/LysC protease mix (Promega) in $50 \mathrm{mM} \mathrm{ABC}$, peptides were desalted on homemade $\mathrm{C} 18$ stage tips (3M, St Paul, MN). After elution from the stage tips, acetonitrile was removed using a SpeedVac and the remaining peptide solution was diluted with buffer $A(0.1 \% \mathrm{FA})$ before loading. Peptides were separated on a $30 \mathrm{~cm}$ pico-tip column $(75 \mu \mathrm{m}$ ID, New Objective) inhouse packed with $1.9 \mu \mathrm{m}$ aqua pure gold C-18 material (dr. Maisch) using 240 gradients (7\% to $80 \%$ ACN $0.1 \%$ FA), delivered by an easy-nLC 1000 (Thermo), and electro-sprayed directly into an Orbitrap Fusion Tribrid Mass Spectrometer (Thermo Scientific). The latter was set in data-dependent Top speed mode with a cycle time of 1 second, in which the full scan over the 400-1500 mass range was performed at a resolution of 240000. Most intense ions (intensity threshold of 5000 ions) were isolated by the quadrupole and fragmented with an HCD collision energy of $30 \%$. The maximum injection time of the ion trap was set to 50 milliseconds with injection of ions for all available parallelizable time. Raw files were analyzed with the Maxquant software version 1.6.10.43 (Cox and Mann, 2008) with acetylation of lysines as well as oxidation of methionine set as variable modifications, and carbamidomethylation of cysteine set as fixed modification. A protein database containing Histone $\mathrm{H} 3$ was searched with both the peptide as well as the protein false discovery rate set to 1\%. Extracted chromatograms of the isotope cluster of the acetylated peptide of H3K27 were made using the software package 
Skyline (MacLean et al. 2010) (PMC2844992)The mass spectrometry proteomics data have been deposited to the ProteomeXchange Consortium via the PRIDE partner repository (http://www.ebi.ac.uk/pride) with the dataset identifiers (PXD018132).

\section{Proximity Ligation Assay (PLA)}

Cells were washed 3 times in PB and incubated in mouse PLUS and rabbit MINUS probes (Sigma Aldrich) according to the manufacturer's protocol. Cells were washed in PB before detection using the in situ PLA detection kit (Sigma-Aldrich) as previously described ${ }^{37}$. Samples were analyzed with a $63 x$ objective on a Leica SP8X.

\section{MPC1 T cell-specific Ko mice}

Mice described in these studies are on the C57BL/6 genetic background and were housed in the animal facility at the University of Utah. MPC1 floxed mice were described previously [51] and crossed to CD4-Cre mouse strains obtained from Jackson laboratories. Mice were ageand sex-matched for all experiments with an age range of 6-12 weeks old. All experiments were approved by the Institutional Animal Care and Use Committee at the University of Utah.

\section{Pdha1 T cell-specific KO mice}

Mice described in these studies received care at the University of Alberta according to the Canadian Council on Animal Care and all procedures were approved by the University of Alberta Health Sciences Animal Welfare Committee. To generate Pdha1 ${ }^{\mathrm{CD} 4+\mathrm{KO}}$ mice,

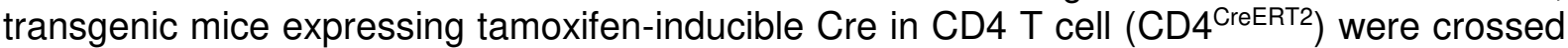
with Pdha1 $1^{\mathrm{fl} / \mathrm{fl}}$ mice (PMID: 29560354) (stock no. 017443; The Jackson Laboratories). Creinduced activation of the knockout was carried out via 5 consecutive intraperitoneal (i.p.) injections of tamoxifen (100 mg/kg/day) in male mice starting at 6 weeks of age. All mice were allowed 3 weeks washout post-tamoxifen administration prior to experimentation.

\section{Isolation and culture of mouse naïve $\mathrm{CD4}^{+} \mathrm{T}$ cells}

Spleens were removed from mice, homogenized, and filtered through a $40 \mu \mathrm{M}$ filter. Red blood cells were then lysed with RBC lysis buffer (Biolegend). Splenocytes were stained with fluorescent antibodies and naïve $\mathrm{CD}^{+} \mathrm{T}$ cells $\left(\mathrm{CD}^{+}{ }^{+} \mathrm{CD} 4^{+} \mathrm{CD} 44^{-}\right)$were purified from splenocytes using FACS sorting.

Purified naïve CD4 ${ }^{+} \mathrm{T}$ cells were then resuspended in RPMI media containing $10 \% \mathrm{FBS}$, Lglutamine, Pen/Strep antibiotics, HEPES, Sodium Pyruvate, and Non-essential amino acids. To activate CD4 ${ }^{+}$T cells, a 96 well plate was coated with $200 \mu \mathrm{l} / \mathrm{well}$ of $5 \mu \mathrm{g} / \mathrm{ml}$ LEAF aCD3 (Biolegend) in PBS for at least 4 hours at $37^{\circ} \mathrm{C}$. $1 \times 10^{5}$ splenic naïve $\mathrm{CD} 4^{+} \mathrm{T}$ cells were cultured in the presence of coated $\alpha \mathrm{CD} 3$ and $2 \mu \mathrm{g} / \mathrm{ml}$ of soluble LEAF aCD28 (Biolegend) for 24 hours. CD69 and CD25 expression were measured by flow cytometry. To measure gene expression of Mpc1, Sema7a, and II2ra, cells were stored in Qiazol lysis reagent (Qiagen) and total RNA was isolated using the miRNeasy kit (Qiagen). Then, cDNA was made using the qScriptTM kit (QuantaBio) and qPCR was performed on an Applied Biosystems QuantStudio 6 Flex using PowerUp (Applied Biosystems) SYBR Green Master mix. Primers for mouse Sema7a and mouse CD25 (II2ra) were acquired from the University of Utah DNA synthesis core and primers for mouse Mpc1 were acquired from IDT. The sequences were: mSema7a $F$ (5'CGTGGCAAGGTCTACCACTT-3'), mSema7a R (5'-GACAGGACCCCTTTGTGGAG-3'), mll2ra F (5'-CACCAGCAACTCCCATGACA-3'), mIl2ra R (5'-TTGGCGTCTCAGATTTGGCT3'), mMpc1 F (5'-GCACGGCCATGGCTGGAGC-3'), and mMpc1 R (5'-GCAACAGAGGGCG AAAGTCATCCG-3').

\section{Experimental Autoimmune Encephalomyelitis}

EAE was performed as we have done previously ${ }^{35}$. Briefly, mice were injected s.c. with $100 \mathrm{ug}$ MOG35-55 peptide (GenScript) emulsified in CFA. Mice were also injected i.p. with $300 \mathrm{ng}$ pertussis toxin (List Biological Laboratories) on days 0 and 2. Clinical scores were recorded regularly. Clinical symptoms were scored on the following criteria: 0 , no symptoms; 0.5 , partially limp tail; 1 , completely limp tail; 1.5, impaired righting reflex; 2 , partial hind-limb 
paralysis; 2.5 , complete hind-limb paralysis; 3 , forelimb weakness; 4 , complete paralysis; 5 , death. At the endpoint of the experiment, brains and spines were isolated and homogenized. Leukocytes were isolated from spines and brains using Percoll gradients. Leukocytes were then restimulated with PMA/ionomycin for 6 hours with Golgi Plug (BD Biosciences). IFNy and IL-17A production by $\mathrm{CD} 4^{+} \mathrm{T}$ cells was then analyzed by flow cytometry.

\section{Statistical Analysis.}

For ChIP-seq and RNA-seq analysis, $p$ values were adjusted with the Benjamini-Hochberg procedure. For ChIP-seq regions with a significantly different H3K27ac signal were defined using a false discovery rate (FDR) $<0.05$. 


\section{References}

1. Jacobs, S.R., et al., Glucose uptake is limiting in T cell activation and requires CD28mediated Akt-dependent and independent pathways. J Immunol, 2008. 180(7): p. 4476-86.

2. Araki, K., et al., mTOR regulates memory CD8 T-cell differentiation. Nature, 2009. 460(7251): p. 108-12.

3. Man, K., et al., The transcription factor IRF4 is essential for TCR affinity-mediated metabolic programming and clonal expansion of T cells. Nat Immunol, 2013. 14(11): p. 1155-65.

4. Freemerman, A.J., et al., Metabolic reprogramming of macrophages: glucose transporter 1 (GLUT1)-mediated glucose metabolism drives a proinflammatory phenotype. J Biol Chem, 2014. 289(11): p. 7884-96.

5. Vaeth, M., et al., Store-Operated $\mathrm{Ca}(2+)$ Entry Controls Clonal Expansion of $T$ Cells through Metabolic Reprogramming. Immunity, 2017. 47(4): p. 664-679 e6.

6. Frauwirth, K.A., et al., The CD28 signaling pathway regulates glucose metabolism. Immunity, 2002. 16(6): p. 769-77.

7. Bauer, D.E., et al., Cytokine stimulation of aerobic glycolysis in hematopoietic cells exceeds proliferative demand. FASEB J, 2004. 18(11): p. 1303-5.

8. Wang, R., et al., The transcription factor Myc controls metabolic reprogramming upon T lymphocyte activation. Immunity, 2011. 35(6): p. 871-82.

9. O'Neill, L.A., R.J. Kishton, and J. Rathmell, $A$ guide to immunometabolism for immunologists. Nat Rev Immunol, 2016. 16(9): p. 553-65.

10. Wang, Y., et al., Calcium regulation of T cell metabolism. Curr Opin Physiol, 2020. 17: p. 207-223.

11. Vander Heiden, M.G., L.C. Cantley, and C.B. Thompson, Understanding the Warburg effect: the metabolic requirements of cell proliferation. Science, 2009. 324(5930): p. 1029-33.

12. Vander Heiden, M.G., et al., Metabolic pathway alterations that support cell proliferation. Cold Spring Harb Symp Quant Biol, 2011. 76: p. 325-34.

13. Lunt, S.Y. and M.G. Vander Heiden, Aerobic glycolysis: meeting the metabolic requirements of cell proliferation. Annu Rev Cell Dev Biol, 2011. 27: p. 441-64.

14. Hosios, A.M., et al., Amino Acids Rather than Glucose Account for the Majority of Cell Mass in Proliferating Mammalian Cells. Dev Cell, 2016. 36(5): p. 540-9.

15. Choudhary, C., et al., The growing landscape of lysine acetylation links metabolism and cell signalling. Nat Rev Mol Cell Biol, 2014. 15(8): p. 536-50.

16. Su, X., K.E. Wellen, and J.D. Rabinowitz, Metabolic control of methylation and acetylation. Curr Opin Chem Biol, 2016. 30: p. 52-60.

17. Kinnaird, A., et al., Metabolic control of epigenetics in cancer. Nat Rev Cancer, 2016. 16(11): p. 694-707.

18. Campbell, S.L. and K.E. Wellen, Metabolic Signaling to the Nucleus in Cancer. Mol Cell, 2018. 71(3): p. 398-408.

19. Peng, M., et al., Aerobic glycolysis promotes $T$ helper 1 cell differentiation through an epigenetic mechanism. Science, 2016. 354(6311): p. 481-484.

20. Bailis, W., et al., Distinct modes of mitochondrial metabolism uncouple $T$ cell differentiation and function. Nature, 2019. 571(7765): p. 403-407.

21. Qiu, J., et al., Acetate Promotes T Cell Effector Function during Glucose Restriction. Cell Rep, 2019. 27(7): p. 2063-2074 e5. 
22. Puleston, D.J., et al., Polyamine metabolism is a central determinant of helper $T$ cell lineage fidelity. Cell, 2021. 184(16): p. 4186-4202 e20.

23. Frauwirth, K.A. and C.B. Thompson, Regulation of $T$ lymphocyte metabolism. J Immunol, 2004. 172(8): p. 4661-5.

24. Trickett, A. and Y.L. Kwan, T cell stimulation and expansion using anti-CD3/CD28 beads. $\mathrm{J}$ Immunol Methods, 2003. 275(1-2): p. 251-5.

25. Sagerstrom, C.G., et al., Activation and differentiation requirements of primary $T$ cells in vitro. Proc Natl Acad Sci U S A, 1993. 90(19): p. 8987-91.

26. Roh, T.Y., et al., The genomic landscape of histone modifications in human $T$ cells. Proc Natl Acad Sci U S A, 2006. 103(43): p. 15782-7.

27. Chang, C.H., et al., Posttranscriptional control of $T$ cell effector function by aerobic glycolysis. Cell, 2013. 153(6): p. 1239-51.

28. Holden, H.M., I. Rayment, and J.B. Thoden, Structure and function of enzymes of the Leloir pathway for galactose metabolism. J Biol Chem, 2003. 278(45): p. 43885-8.

29. Aguer, C., et al., Galactose enhances oxidative metabolism and reveals mitochondrial dysfunction in human primary muscle cells. PLoS One, 2011. 6(12): p. e28536.

30. Zachar, Z., et al., Non-redox-active lipoate derivates disrupt cancer cell mitochondrial metabolism and are potent anticancer agents in vivo. J Mol Med (Berl), 2011. 89(11): p. 1137-48.

31. Jun, S., et al., The requirement for pyruvate dehydrogenase in leukemogenesis depends on cell lineage. Cell Metab, 2021. 33(9): p. 1777-1792 e8.

32. Shi, L.Z., et al., HIF1alpha-dependent glycolytic pathway orchestrates a metabolic checkpoint for the differentiation of TH17 and Treg cells. J Exp Med, 2011. 208(7): p. 1367-76.

33. Sutendra, G., et al., A nuclear pyruvate dehydrogenase complex is important for the generation of acetyl-CoA and histone acetylation. Cell, 2014. 158(1): p. 84-97.

34. Paik, W.K., et al., Nonenzymatic acetylation of histones with acetyl-CoA. Biochim Biophys Acta, 1970. 213(2): p. 513-22.

35. Nagampalli, R.S.K., et al., Human mitochondrial pyruvate carrier 2 as an autonomous membrane transporter. Sci Rep, 2018. 8(1): p. 3510.

36. Colca, J.R., et al., Identification of a mitochondrial target of thiazolidinedione insulin sensitizers (mTOT)--relationship to newly identified mitochondrial pyruvate carrier proteins. PLoS One, 2013. 8(5): p. e61551.

37. Divakaruni, A.S., et al., Thiazolidinediones are acute, specific inhibitors of the mitochondrial pyruvate carrier. Proc Natl Acad Sci U S A, 2013. 110(14): p. 5422-7.

38. Ramstead, A.G., et al., Mitochondrial Pyruvate Carrier 1 Promotes Peripheral T Cell Homeostasis through Metabolic Regulation of Thymic Development. Cell Rep, 2020. 30(9): p. 2889-2899 e6.

39. Koishi, M., et al., The effects of KNK437, a novel inhibitor of heat shock protein synthesis, on the acquisition of thermotolerance in a murine transplantable tumor in vivo. Clin Cancer Res, 2001. 7(1): p. 215-9.

40. van Loosdregt, J., et al., Stabilization of the transcription factor Foxp3 by the deubiquitinase USP7 increases Treg-cell-suppressive capacity. Immunity, 2013. 39(2): p. 259-71.

41. van Loosdregt, J., et al., Canonical Wnt signaling negatively modulates regulatory $T$ cell function. Immunity, 2013. 39(2): p. 298-310. 
42. Fox, C.J., P.S. Hammerman, and C.B. Thompson, Fuel feeds function: energy metabolism and the T-cell response. Nat Rev Immunol, 2005. 5(11): p. 844-52.

43. Gerriets, V.A. and J.C. Rathmell, Metabolic pathways in T cell fate and function. Trends Immunol, 2012. 33(4): p. 168-73.

44. Jones, R.G. and C.B. Thompson, Revving the engine: signal transduction fuels $T$ cell activation. Immunity, 2007. 27(2): p. 173-8.

45. Cham, C.M. and T.F. Gajewski, Glucose availability regulates IFN-gamma production and p70S6 kinase activation in CD8+ effector T cells. J Immunol, 2005. 174(8): p. 46707.

46. Macintyre, A.N., et al., The glucose transporter Glut1 is selectively essential for CD4 T cell activation and effector function. Cell Metab, 2014. 20(1): p. 61-72.

47. Blagih, J., et al., The energy sensor AMPK regulates $T$ cell metabolic adaptation and effector responses in vivo. Immunity, 2015. 42(1): p. 41-54.

48. Ho, P.C., et al., Phosphoenolpyruvate Is a Metabolic Checkpoint of Anti-tumor T Cell Responses. Cell, 2015. 162(6): p. 1217-28.

49. Takahashi, H., et al., Nucleocytosolic acetyl-coenzyme a synthetase is required for histone acetylation and global transcription. Mol Cell, 2006. 23(2): p. 207-17.

50. Menk, A.V., et al., Early TCR Signaling Induces Rapid Aerobic Glycolysis Enabling Distinct Acute T Cell Effector Functions. Cell Rep, 2018. 22(6): p. 1509-1521.

51. Schell, J.C., et al., Control of intestinal stem cell function and proliferation by mitochondrial pyruvate metabolism. Nat Cell Biol, 2017. 19(9): p. 1027-1036. 
A

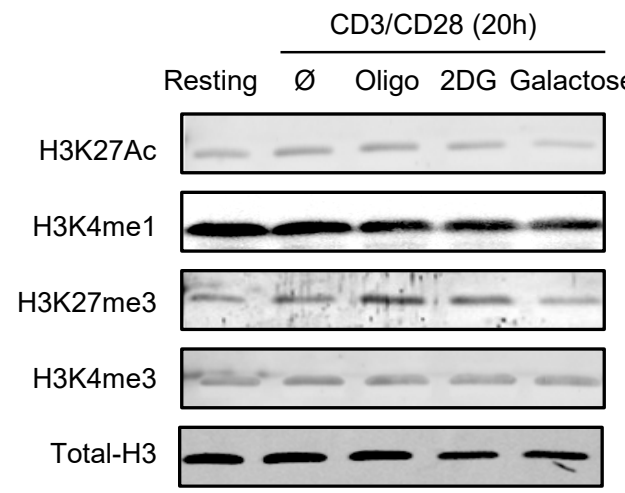

B

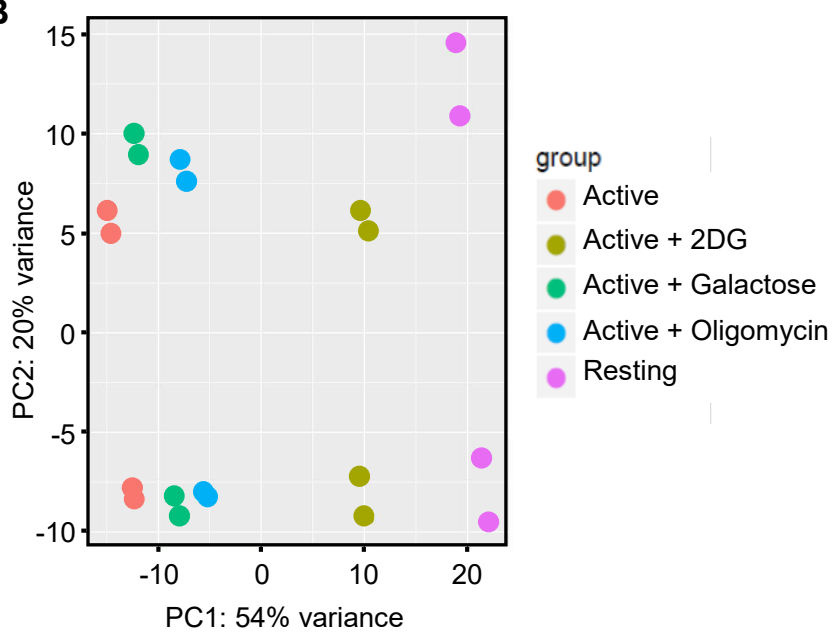

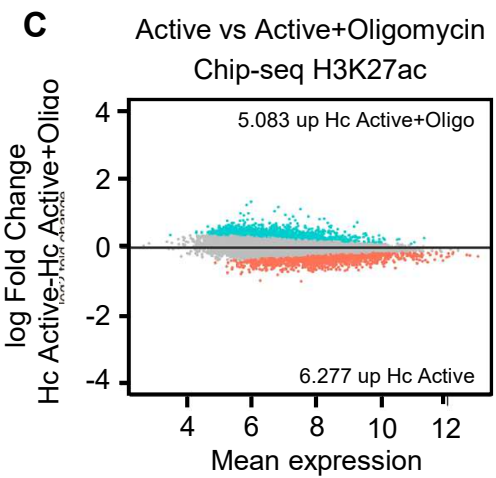

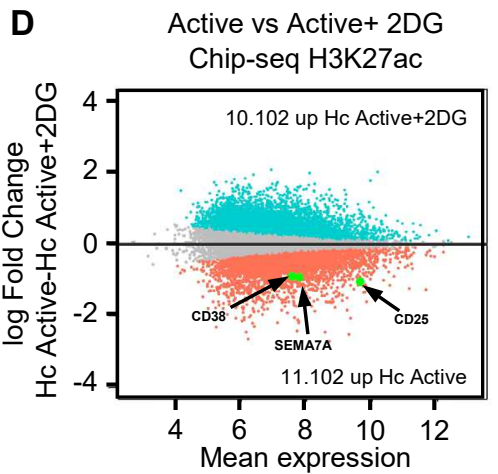

E

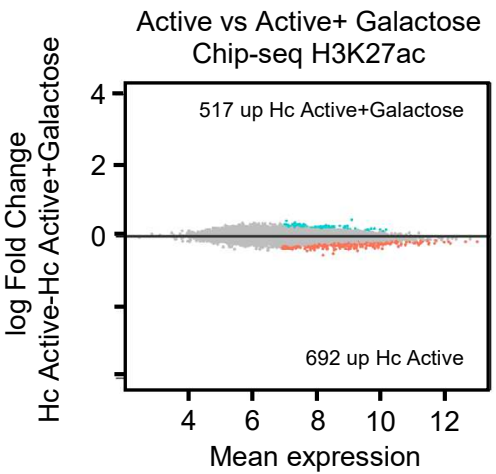

F

G

${ }^{13} \mathrm{C}$ Acetyl-H3K27

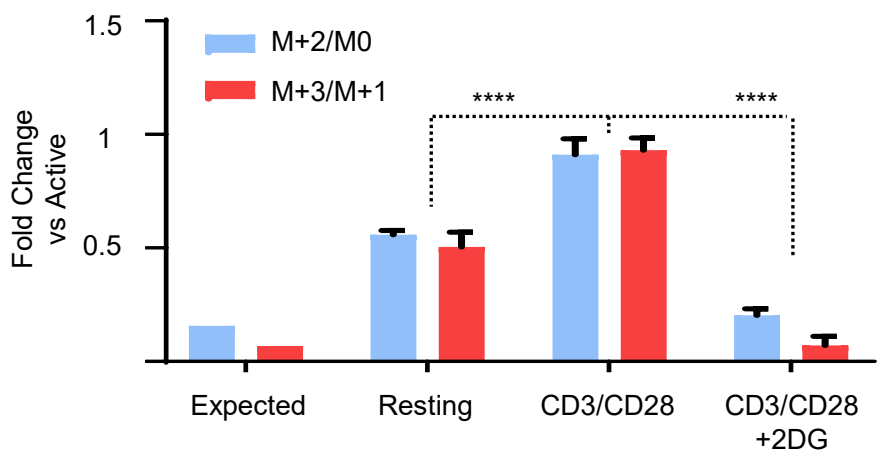


A

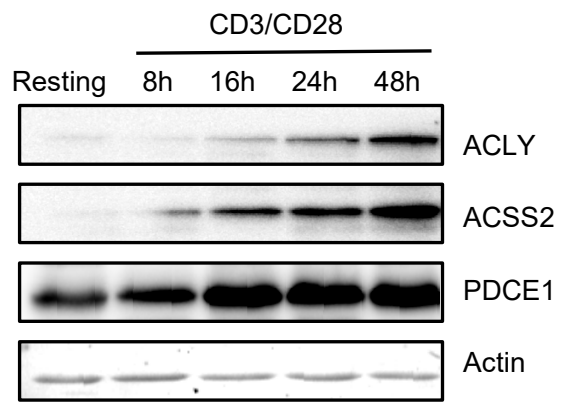

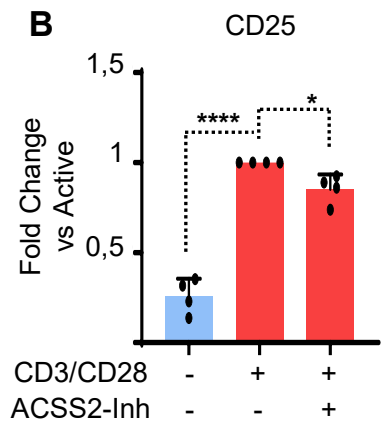

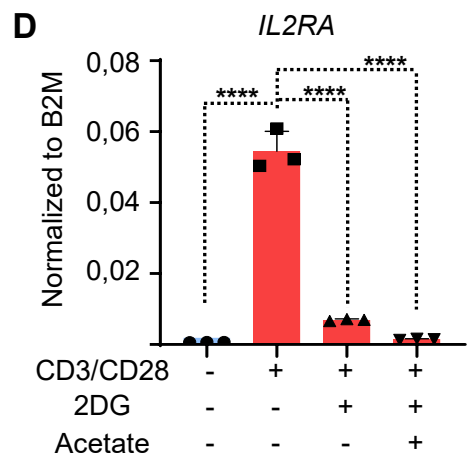

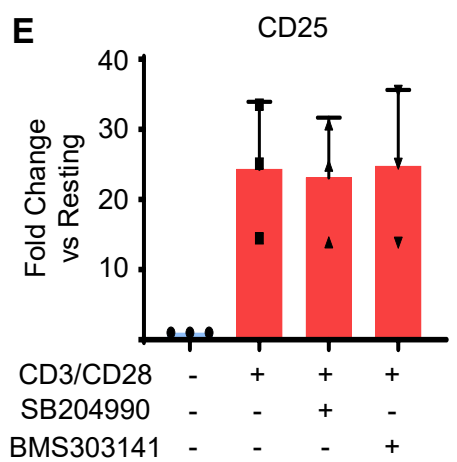

$\mathbf{F}$

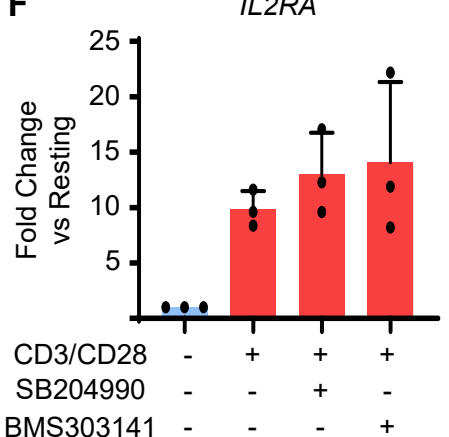

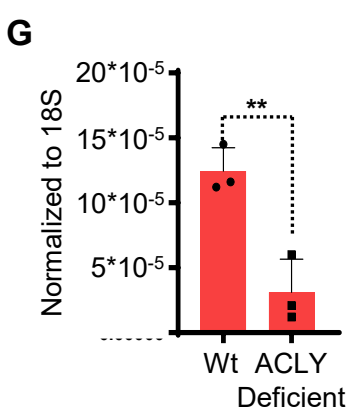

K

H

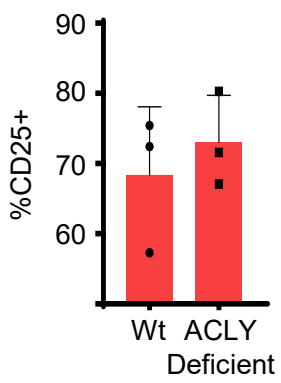

I

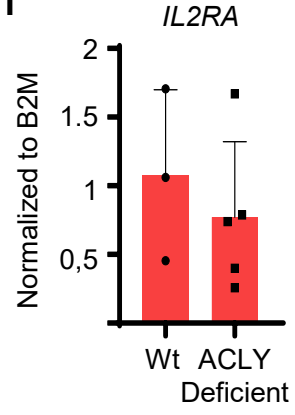

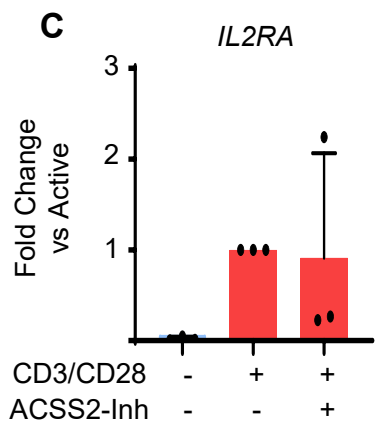

J

ACLY Deficient Active vs Wt Active RNA-seq
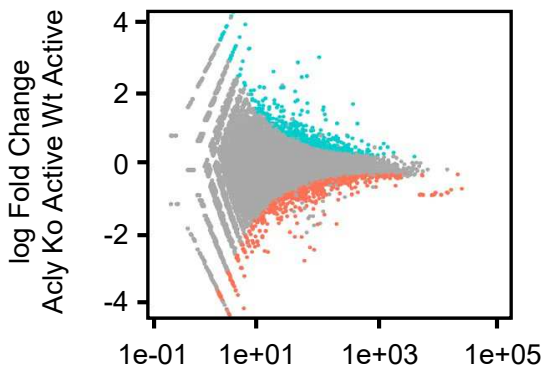

Mean expression
K Genes Up RNA T cell activation

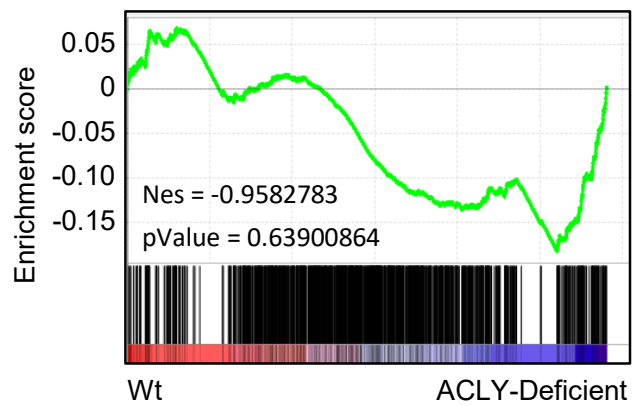

L Activation Genes Regulated by Glycolysis

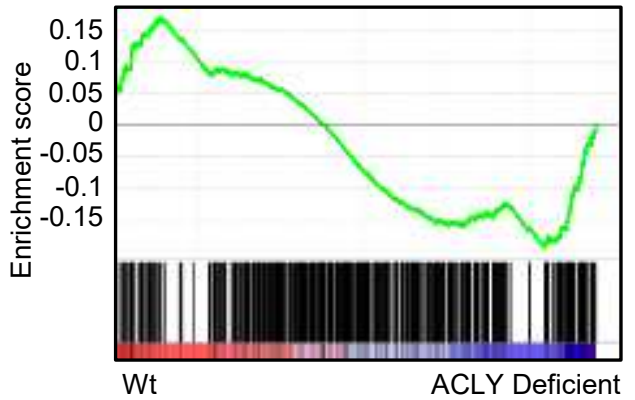


A

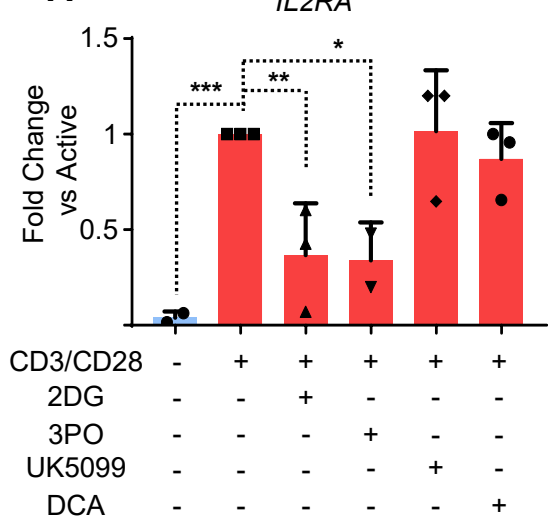

B

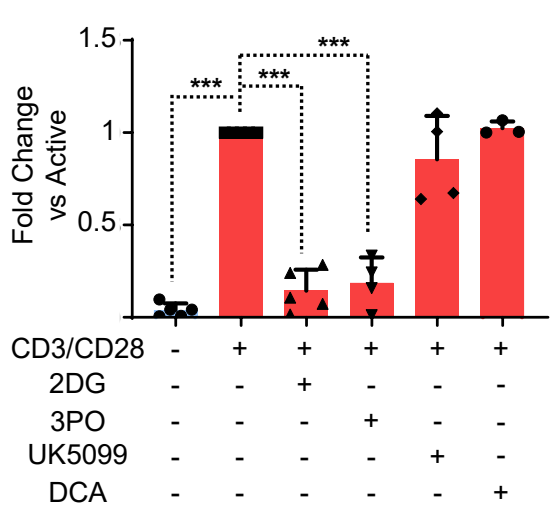

C CD25

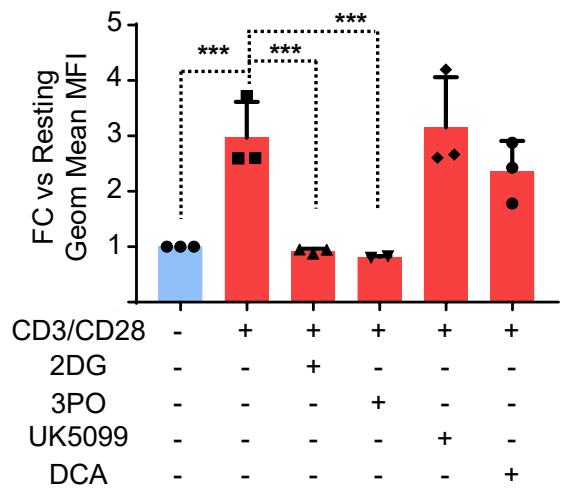

D

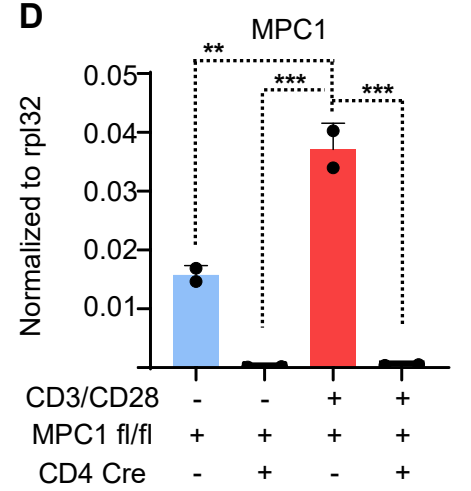

E

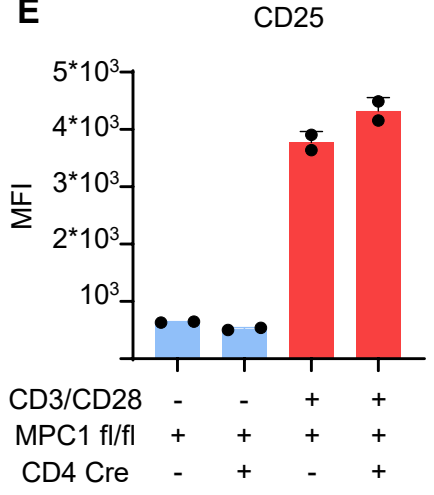

F

II2ra

G

EAE Clinical score

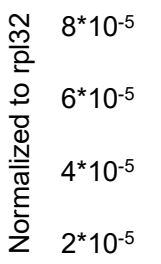

$\mathrm{CD} 3 / \mathrm{CD} 28$

$\mathrm{MPC} 1 \mathrm{fl} / \mathrm{fl}++++$

CD4 Cre - + - +

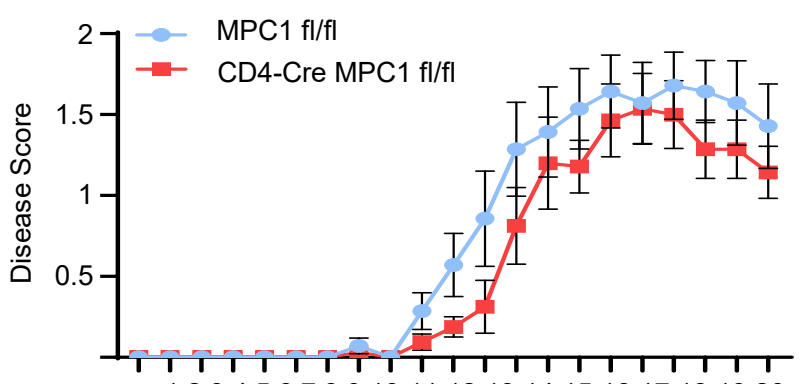

1234567891011121314151617181920

Days
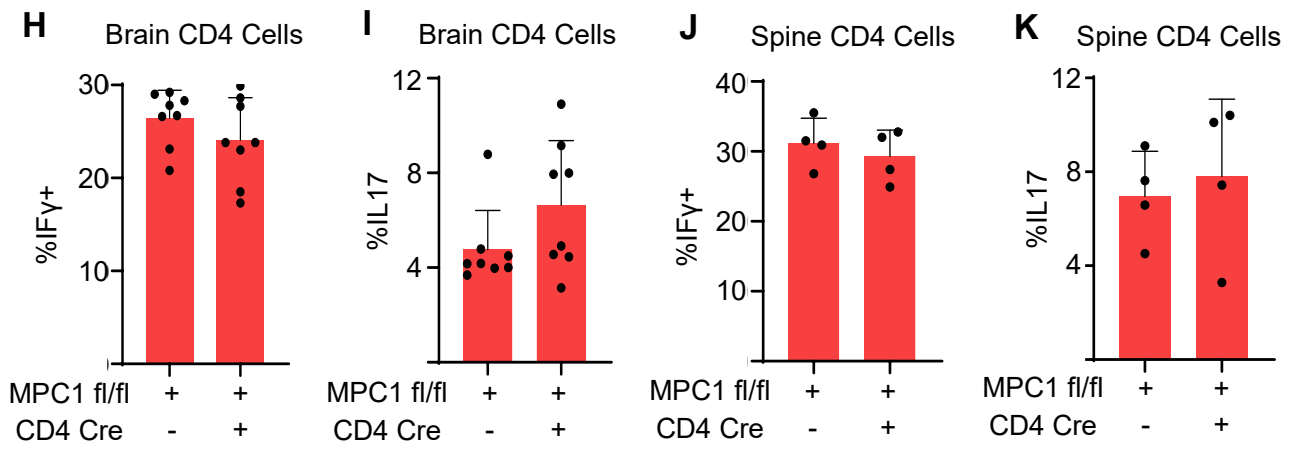
A

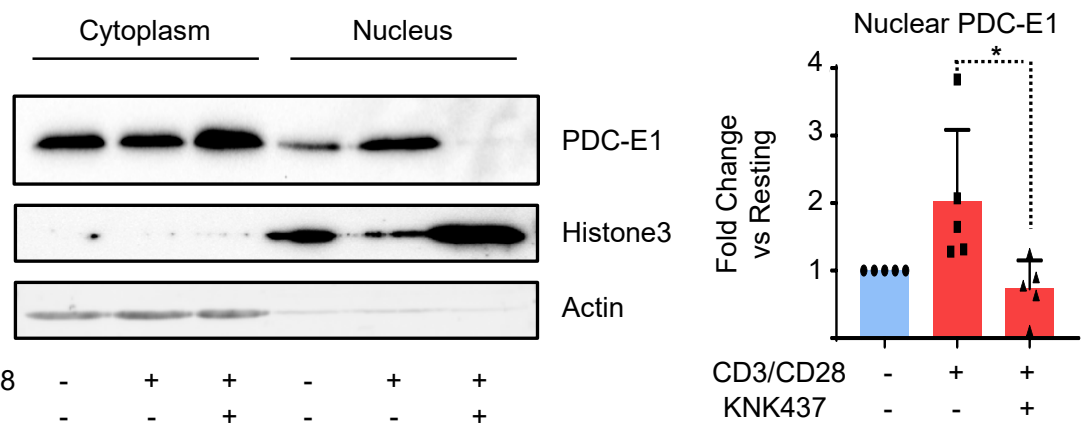

$\begin{array}{ccccccc}\mathrm{CD} 3 / \mathrm{CD} 28 & - & + & + & - & + & + \\ \mathrm{KNK} 437 & - & - & + & - & - & +\end{array}$

B

CD25

CD38

SEMA7A
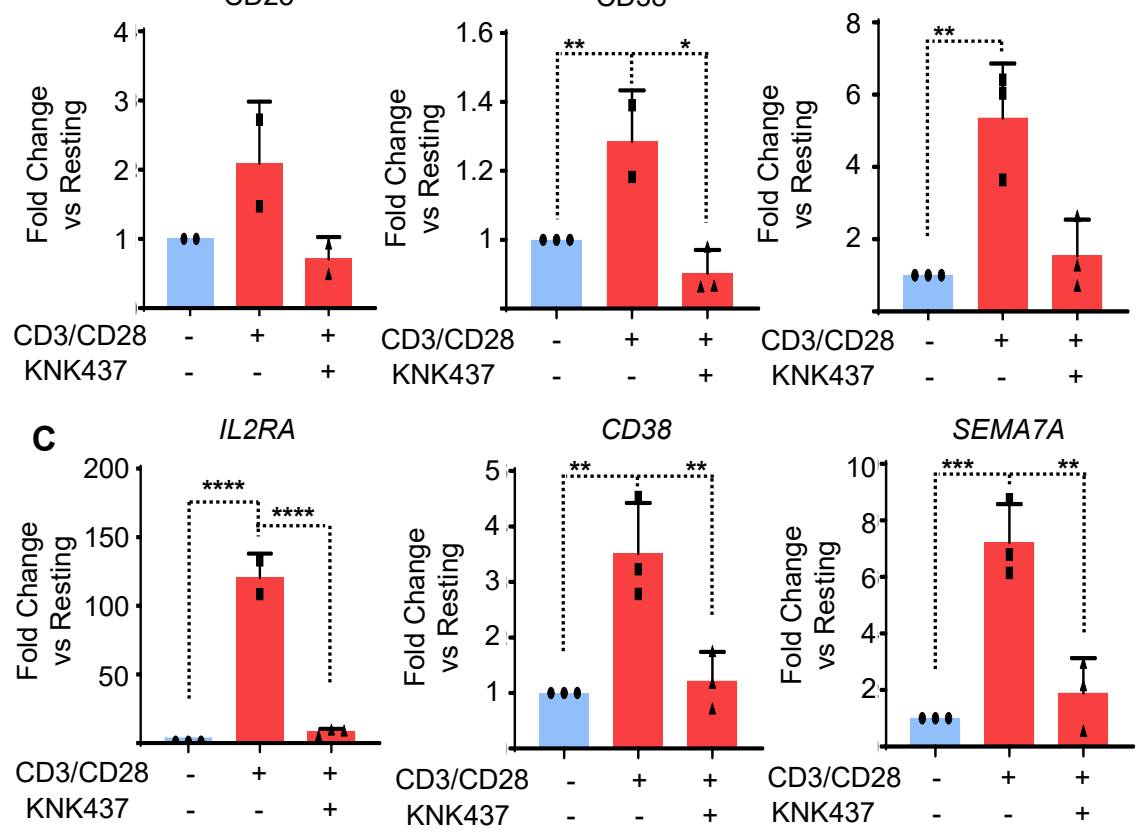

D

Resting

PDC-E1-H3K27ac

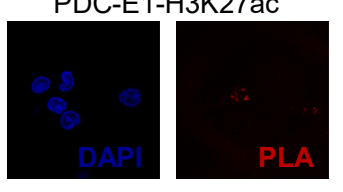

Active

Resting

PDC-E1-H3K27ac

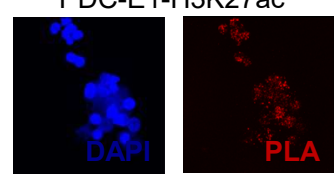

PDC-E1-P300

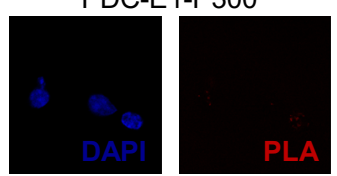

CD3/CD28

PDC-E1-P300
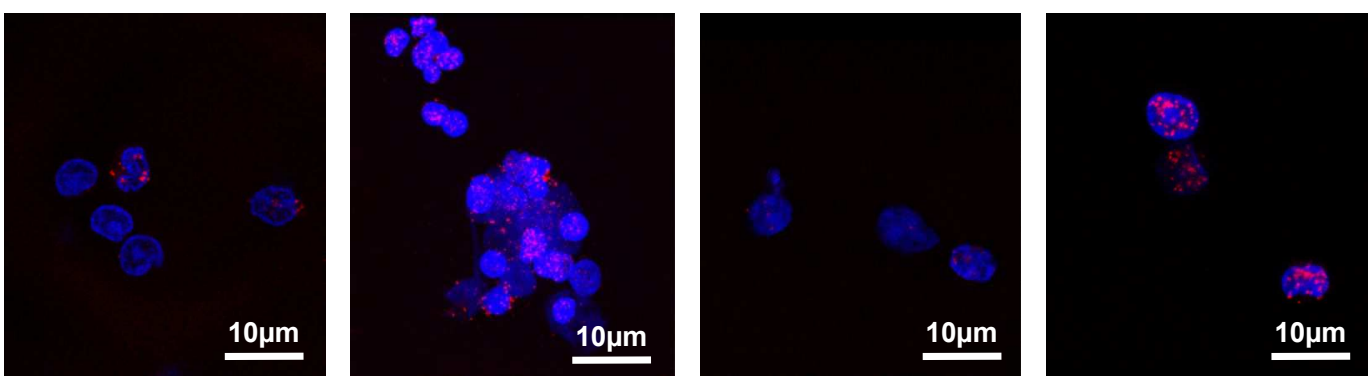
A

Hc Active vs Hc Resting RNA-seq

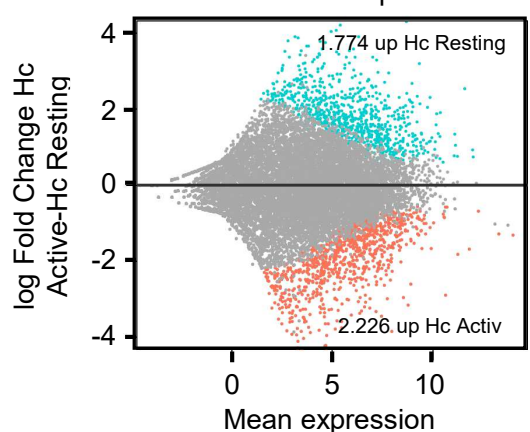

C Hc Active vs Hc Resting Chip-seq H3K27ac

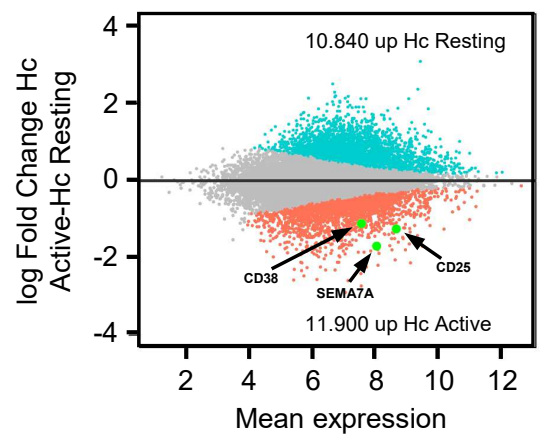

E Genes up Regulated in Hc Active:

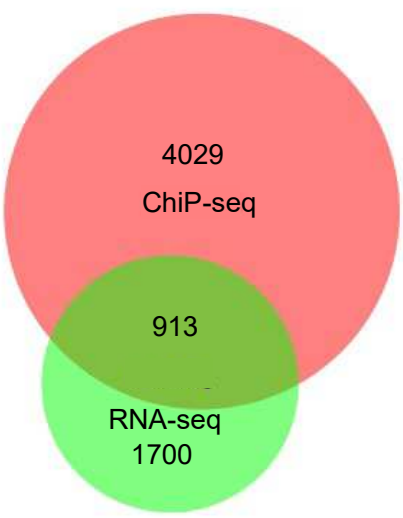

B

Gene-ontology on genes that were up-regulated in RNA-seq in Hc Activated.

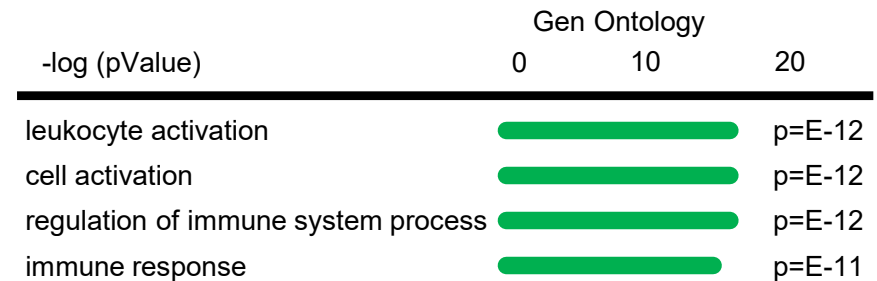

D

Gene-ontology on genes that were up-regulated in Chip-seq in Hc Activated. Gen Ontology

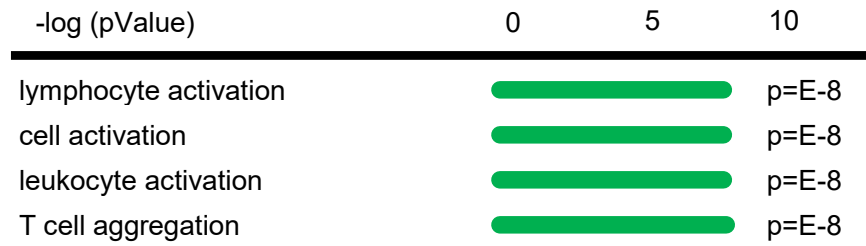

F Gene-ontology on genes that were up-regulated Hc Active in RNA-seq and Chip-seq.

\begin{tabular}{lll}
-log ( $p$ Value) & 0 & 2 \\
\hline phagocytosis & $p=E-3$ \\
cell activation & $p=E-3$ \\
leukocyte activation & $p=E-2$ \\
lymphocyte activation & $p=E-3$
\end{tabular}

\section{Genes Down Chip}
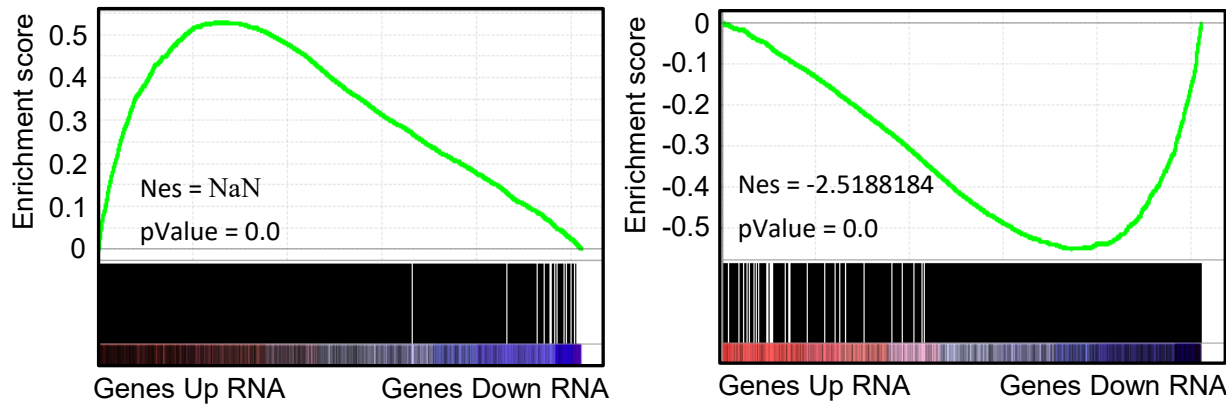

Genes Up RNA

Genes Down RNA 
A
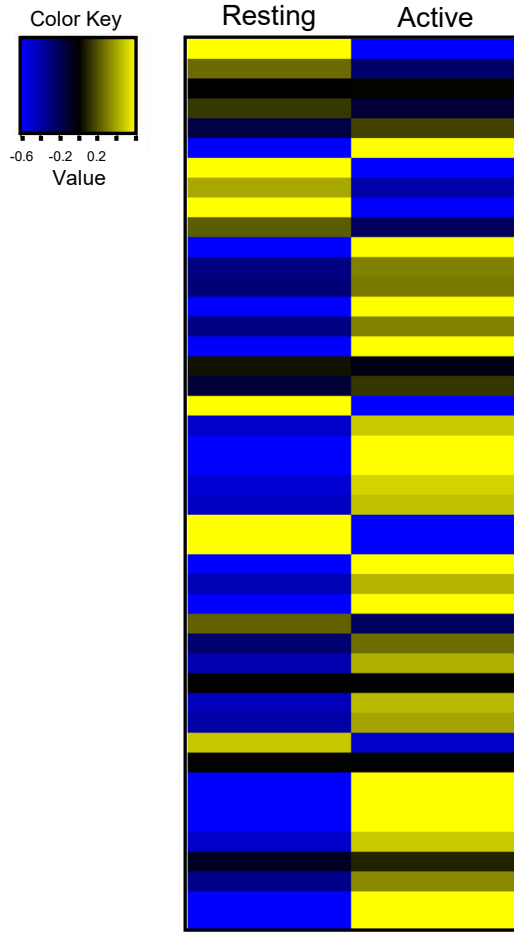

ACSS1

ACSS2

ADH5

AKR1A1

ALDH1B1

ALDH2

ALDH3A2

ALDH3B1

ALDH9A 1

ALDOA

ALDOC

BPGM

DLAT

ELD

ENO2

ENO3

FBP1

GALM

GALM

GAPD

GPI

HKR

HK3

HKDC1

HKDC1

LDHA

DHC

PANK1

ACK2

PCK2

PCHA1

PDHB

PFKFB2

PFKFB3

PFKL

PFKL

PFKM

PFKP

PGAM1

PGK1

PGM1

PGM2

PKM

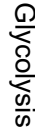

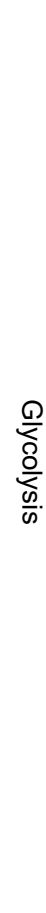

B

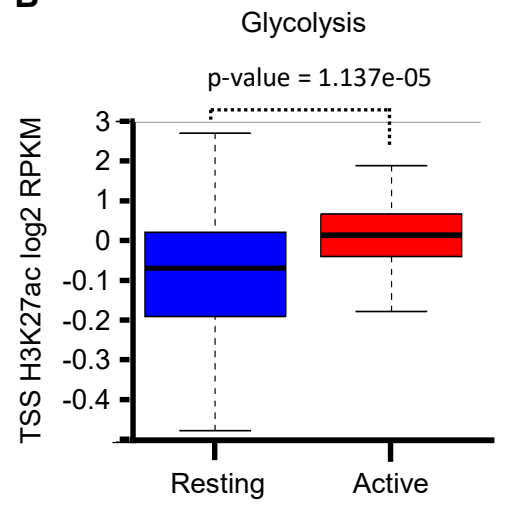


A

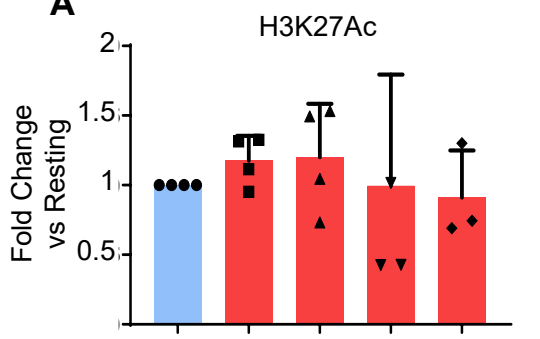

Resting $\varnothing$ Oligo 2DGGalactose

CD3/CD28+

$24 \mathrm{~h}$

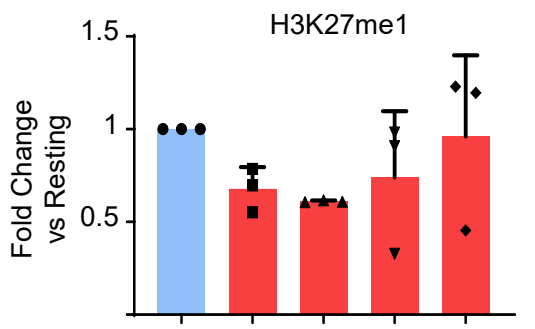

Resting $\varnothing$ Oligo 2DG Galactose

CD3/CD28+

$24 \mathrm{~h}$

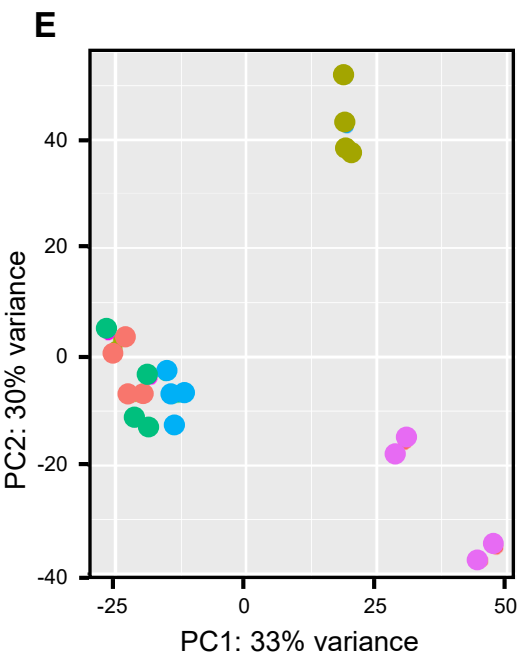

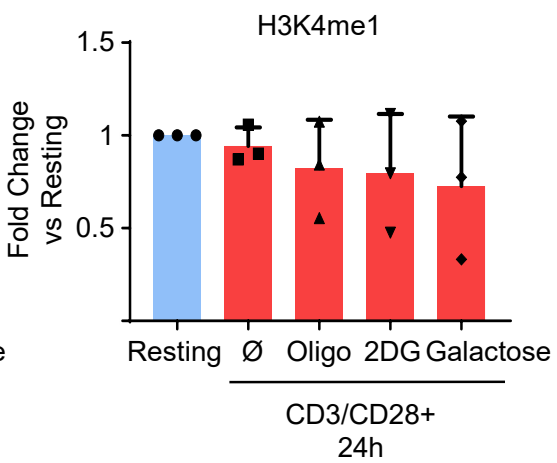

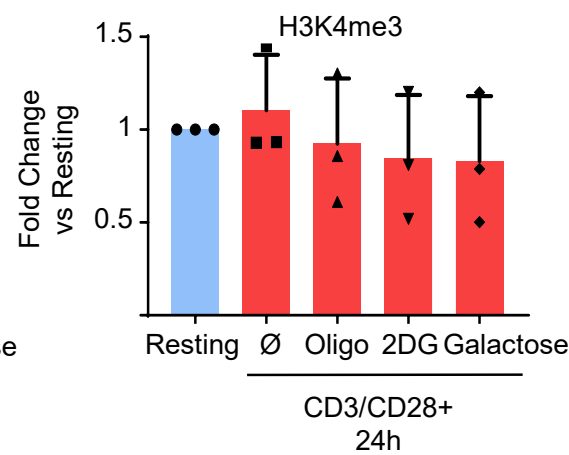

$24 \mathrm{~h}$ group

Active

Active + 2DG

Active + Galactose

Active + Oligomycin

Resting
B Active vs Active+Oligomycin

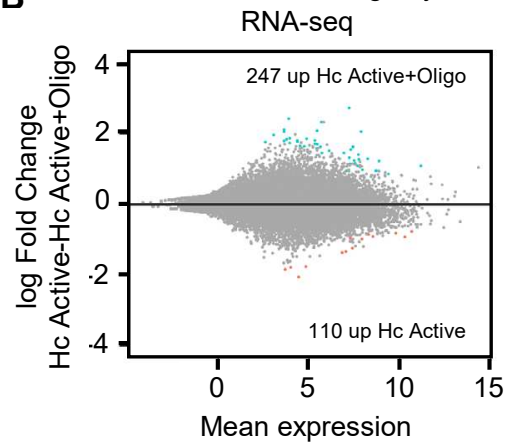

C Active vs Active+ 2DG
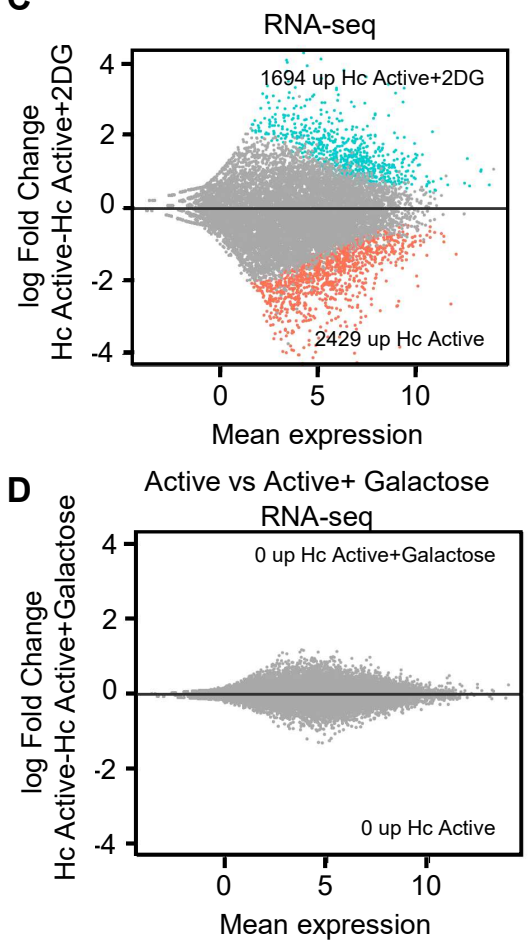

F

Up Active Chip Down 2DG RNA


A Gene-ontology on up-regulated genes during activation dependent of glycolysis.

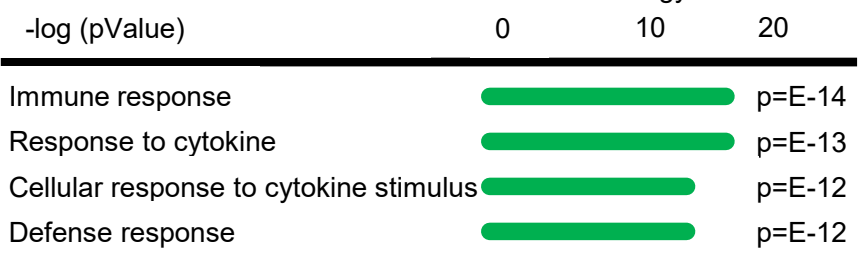

C

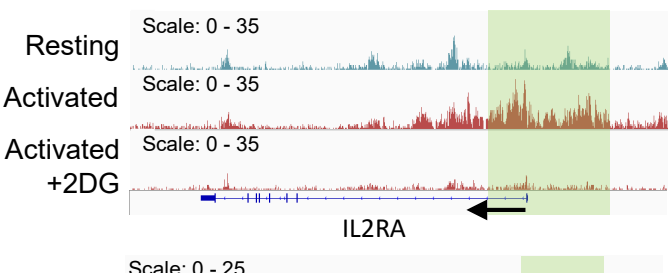

Resting

Activated Scale: $0-25$

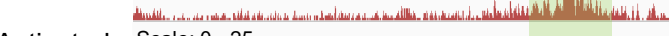

Activated+ Scale: 0 - 25

2DG SEMA7A

$\begin{array}{cc}\text { Resting } & \text { Scale: } 0 \text { - } 30 \\ \text { Activated } & \text { Scale: } 0 \text { - 30 } \\ \text { Activated+ } & \text { Scale: } 0 \text { - } 30 \\ \text { 2DG } & \text { CD38 }\end{array}$

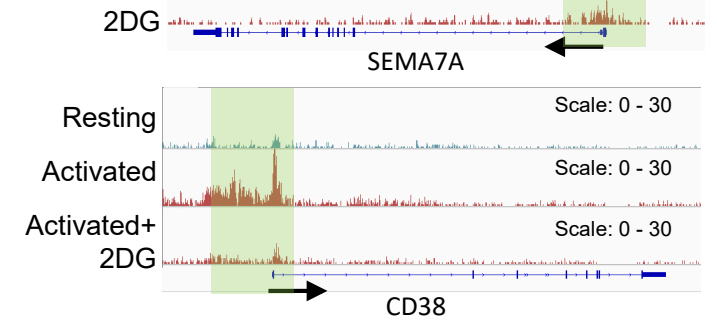

B Selected genes associated with increased H3K27ac and expression in Activated T cells

\begin{tabular}{ccc}
$\begin{array}{c}\text { Interleukin } \\
\text { Receptors }\end{array}$ & $\begin{array}{c}\text { CD } \\
\text { Markers }\end{array}$ & $\begin{array}{c}\text { Associated with } \\
\text { T Activation }\end{array}$ \\
\hline IL2RA (CD25) & CD38 & SEMA7A \\
IL1R2 & CD109 & NFKBIA \\
IL7R & CD27 & STAT3
\end{tabular}


A
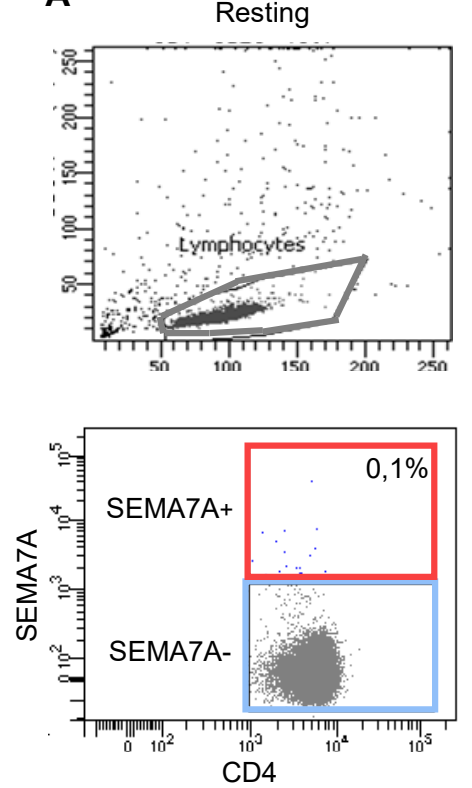

CD3/CD28
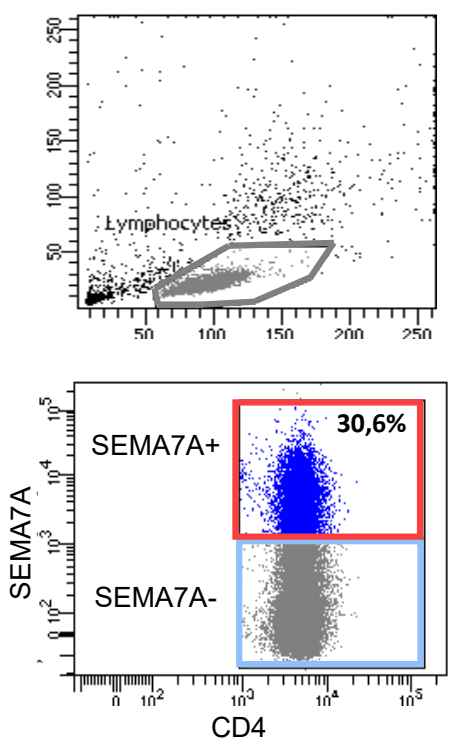

B
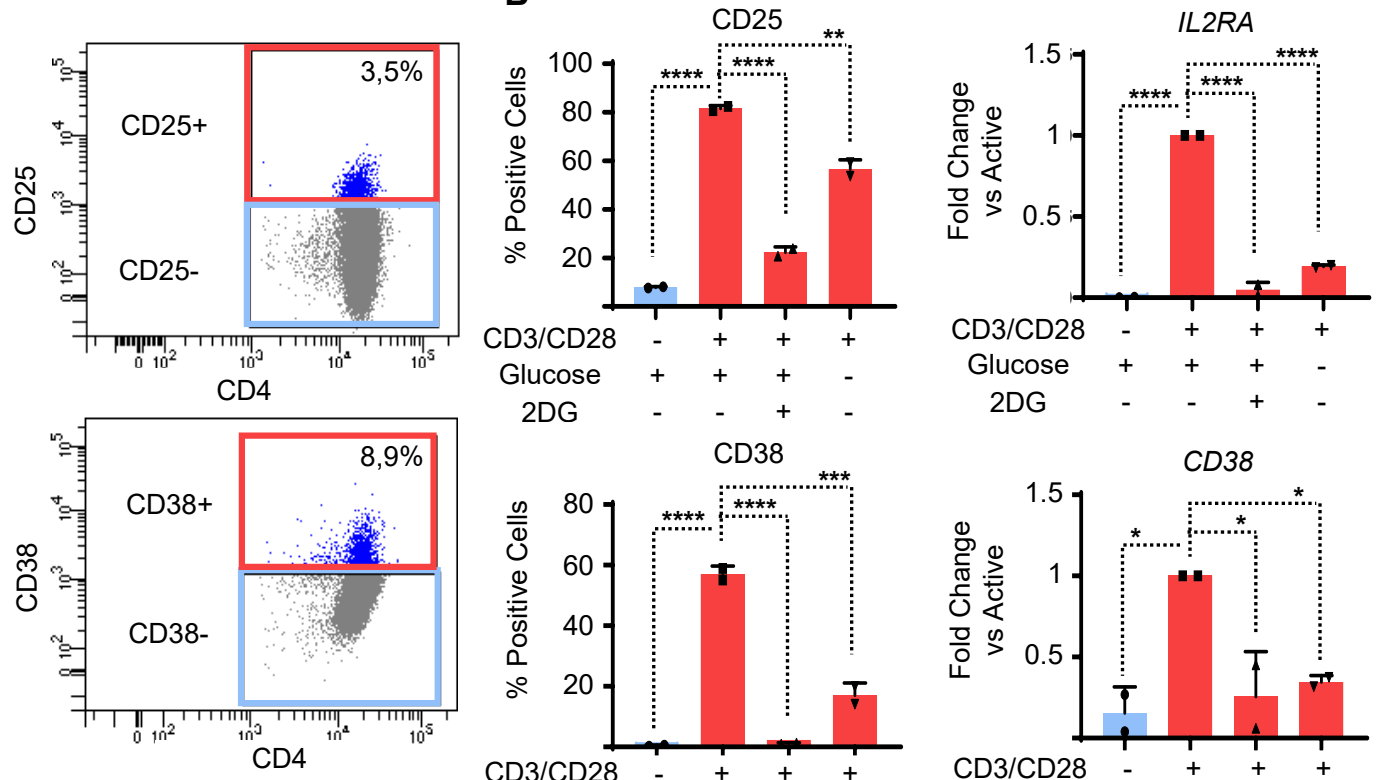

2DG
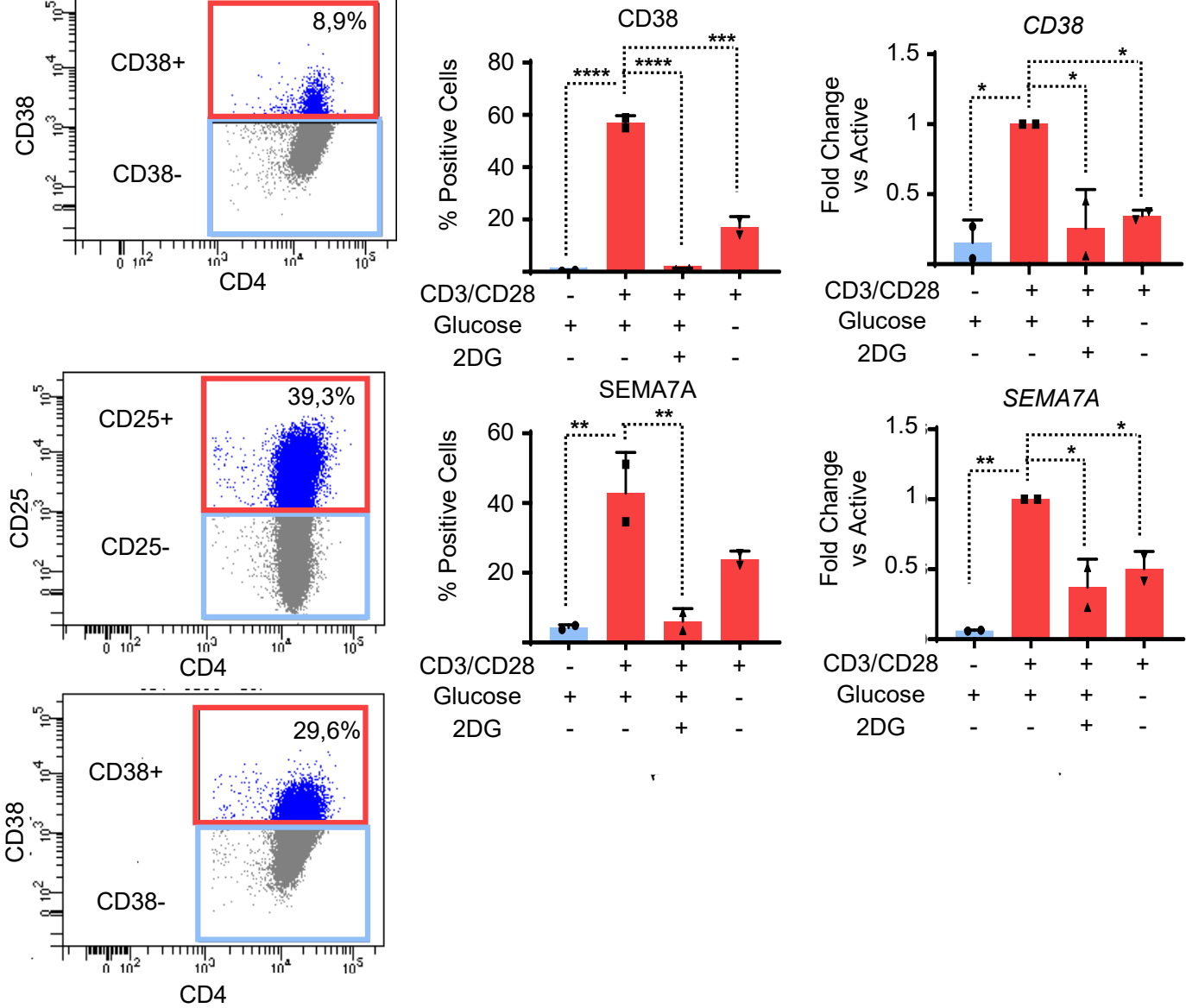

C
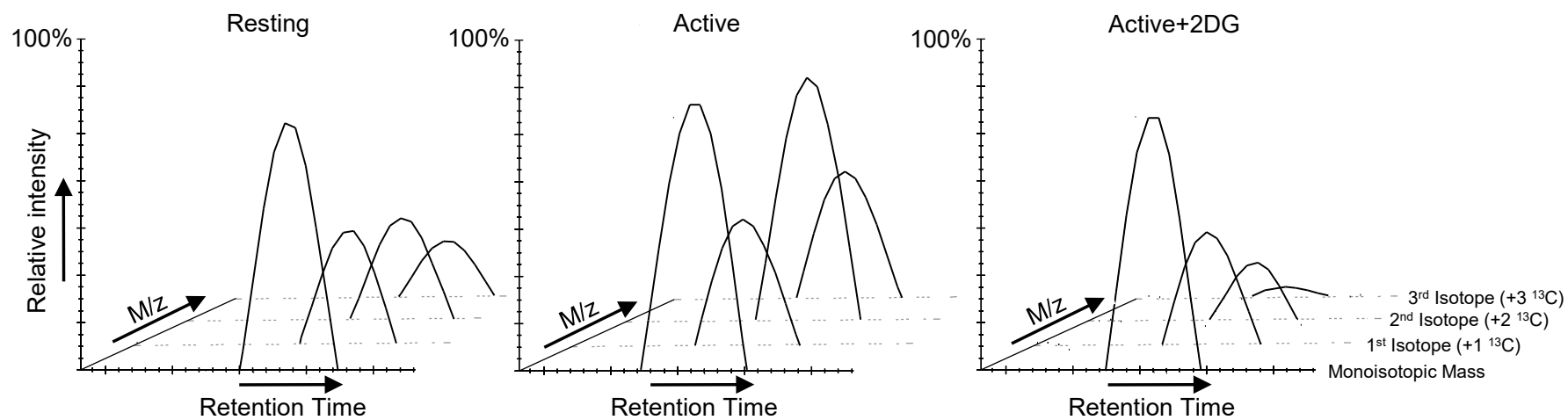
A

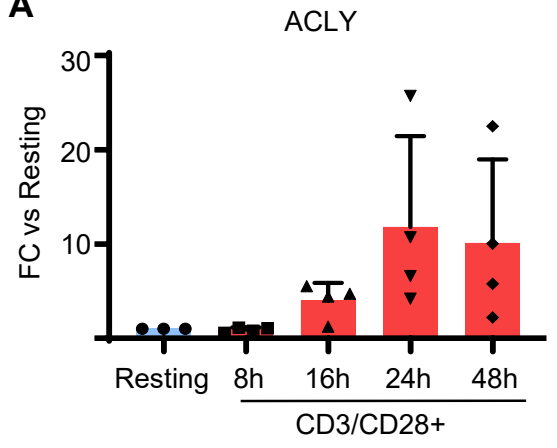

Acss2

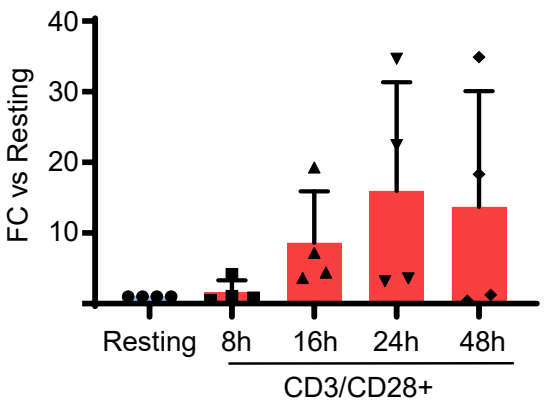

PDCE1

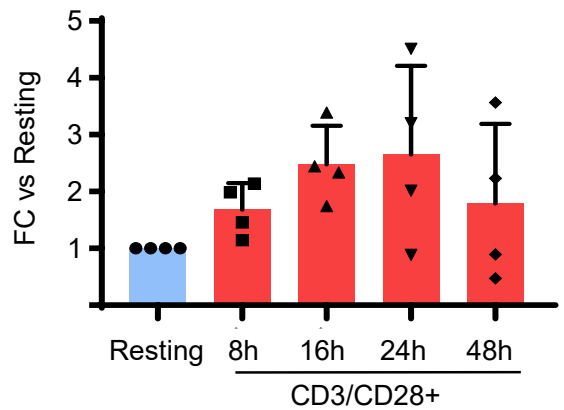


A $\quad$ CD38

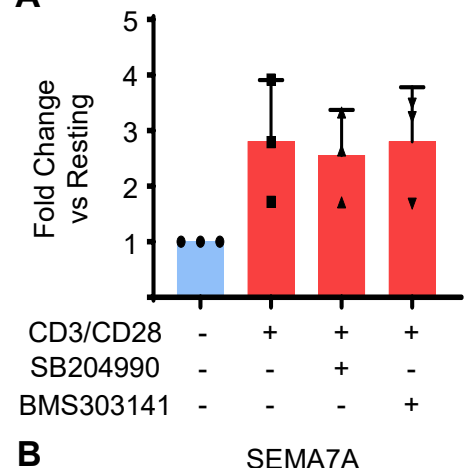

B

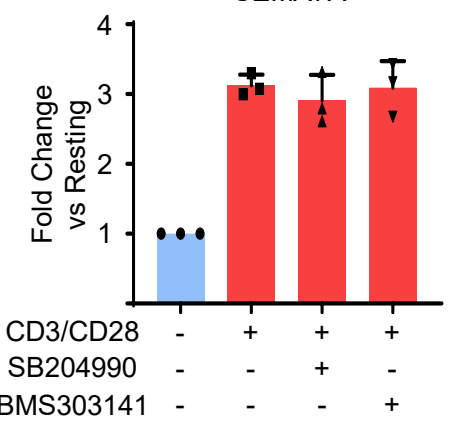

C

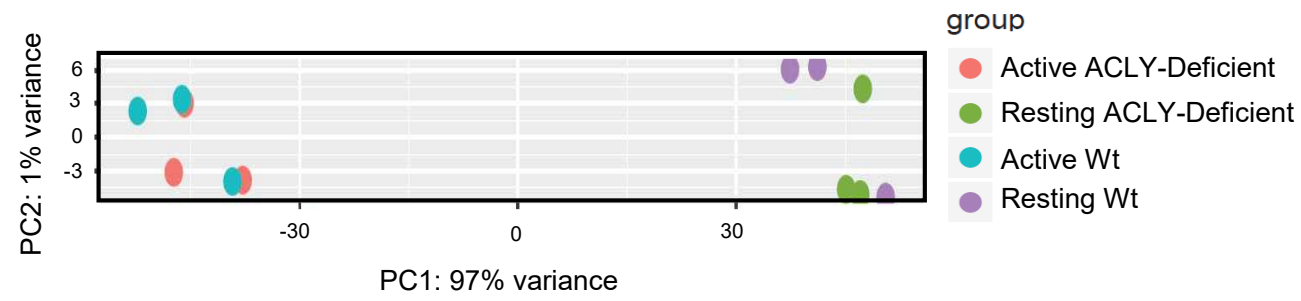

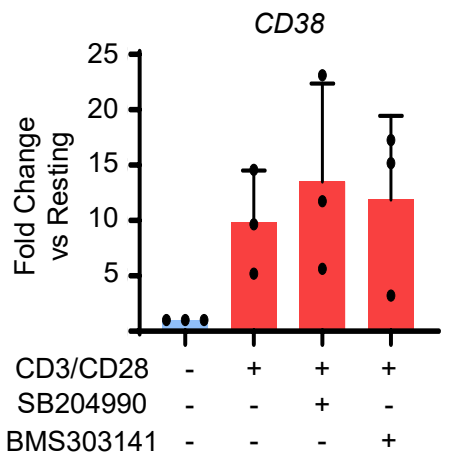

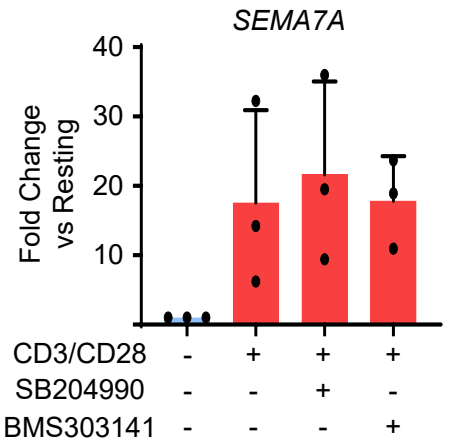

PC1: 97\% variance 

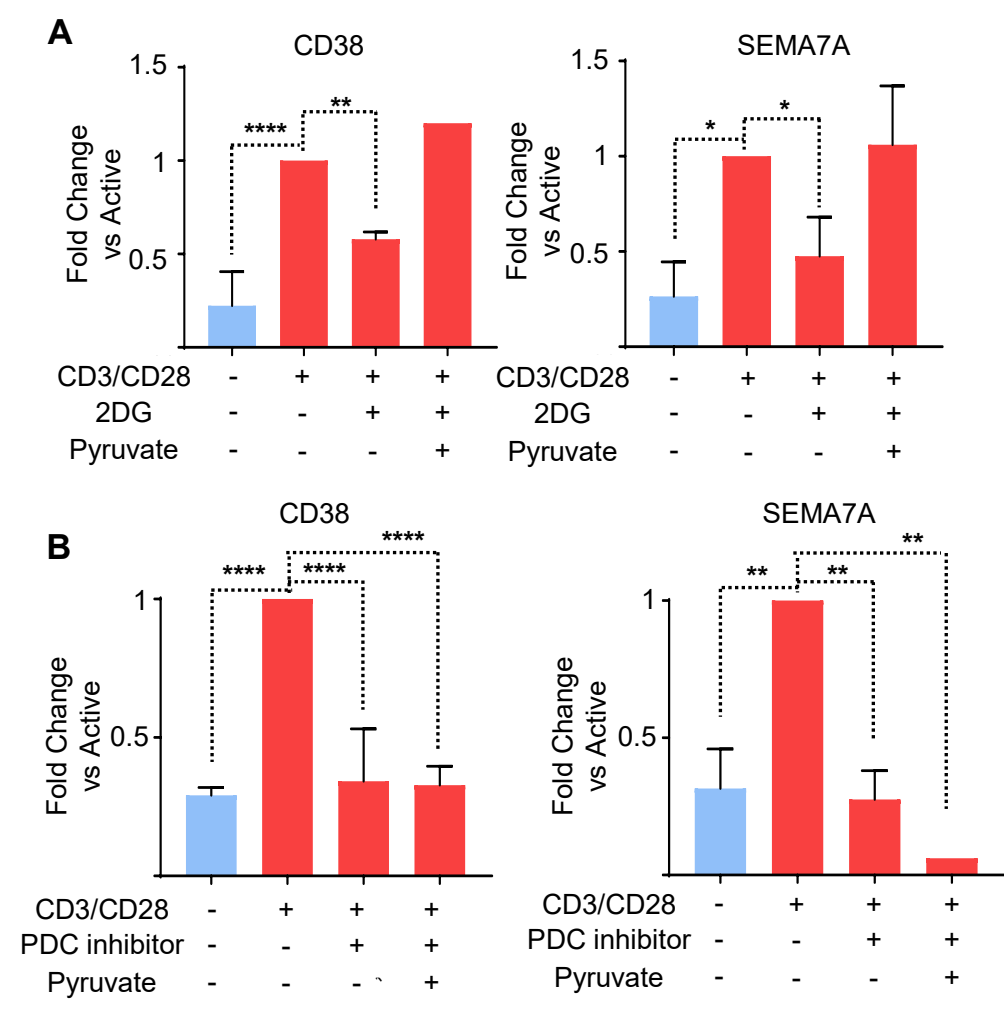

$$
\text { C } \quad \text { CD38 }
$$

SEMA7A
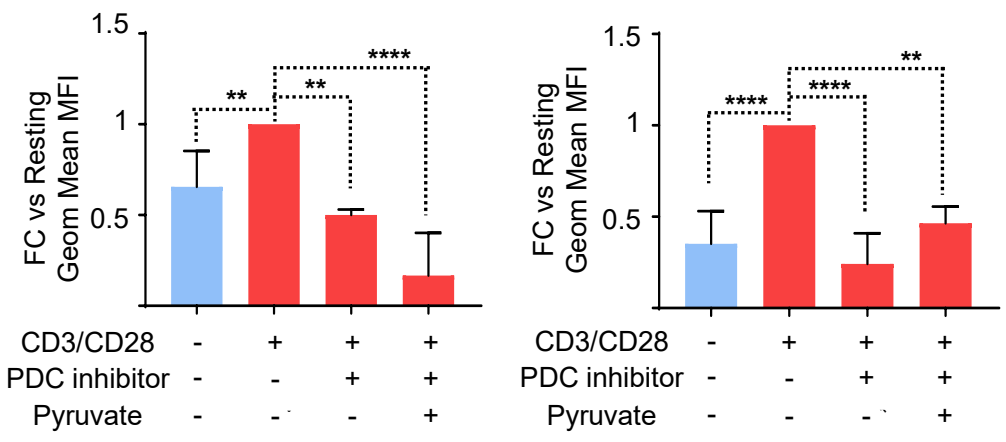

D
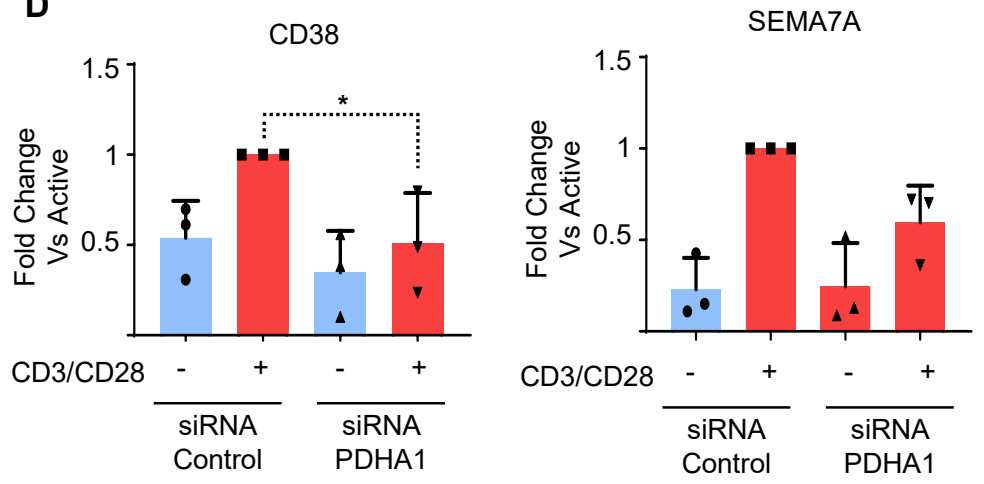
PDC-E1

A

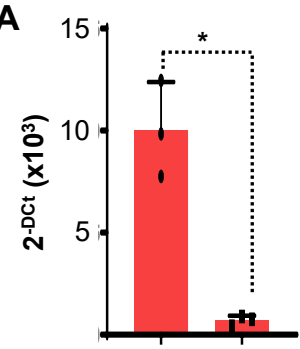

Wt Deficient

C

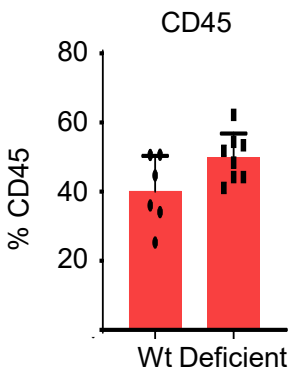

PDHA1
B

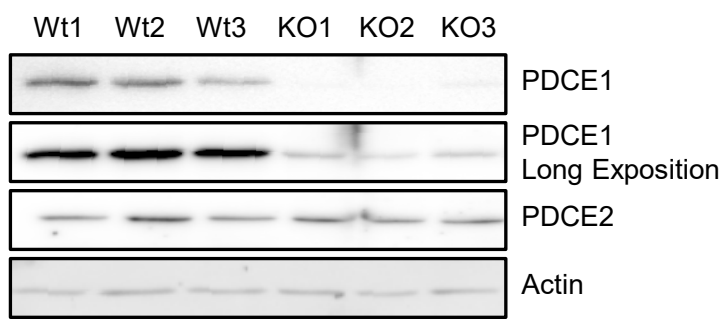

Naïve CD4

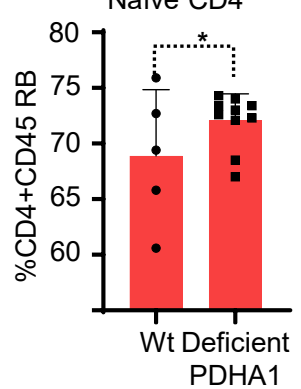

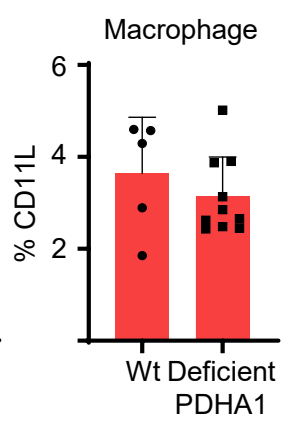

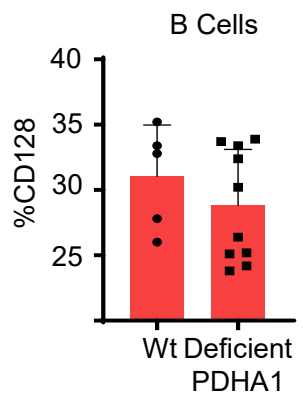

PDC-E1

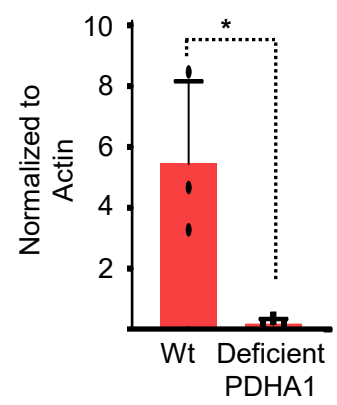

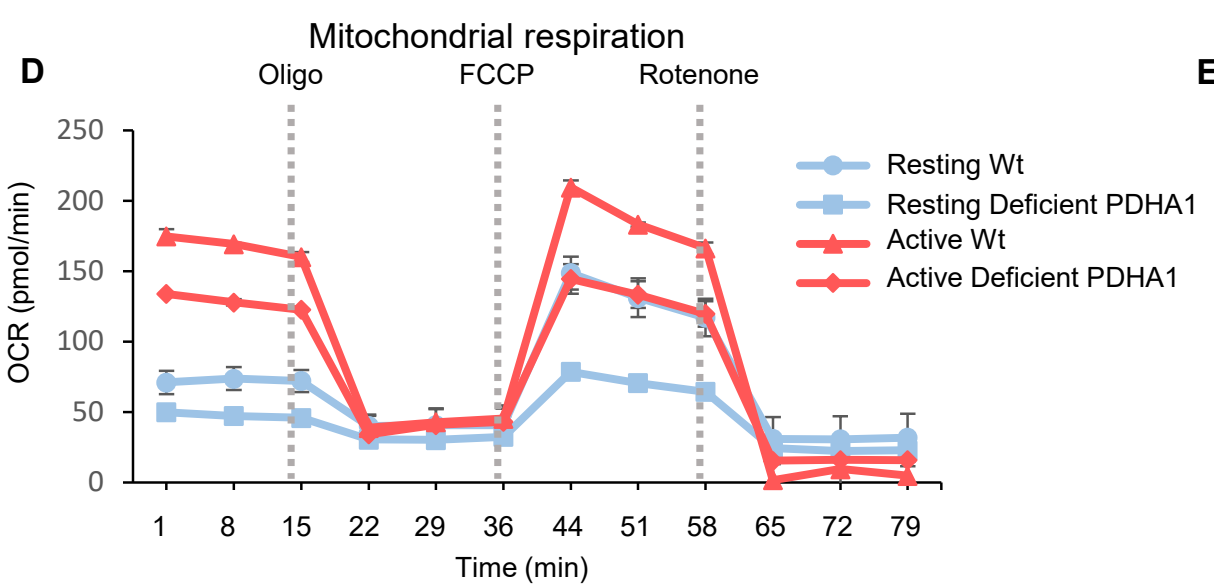

E
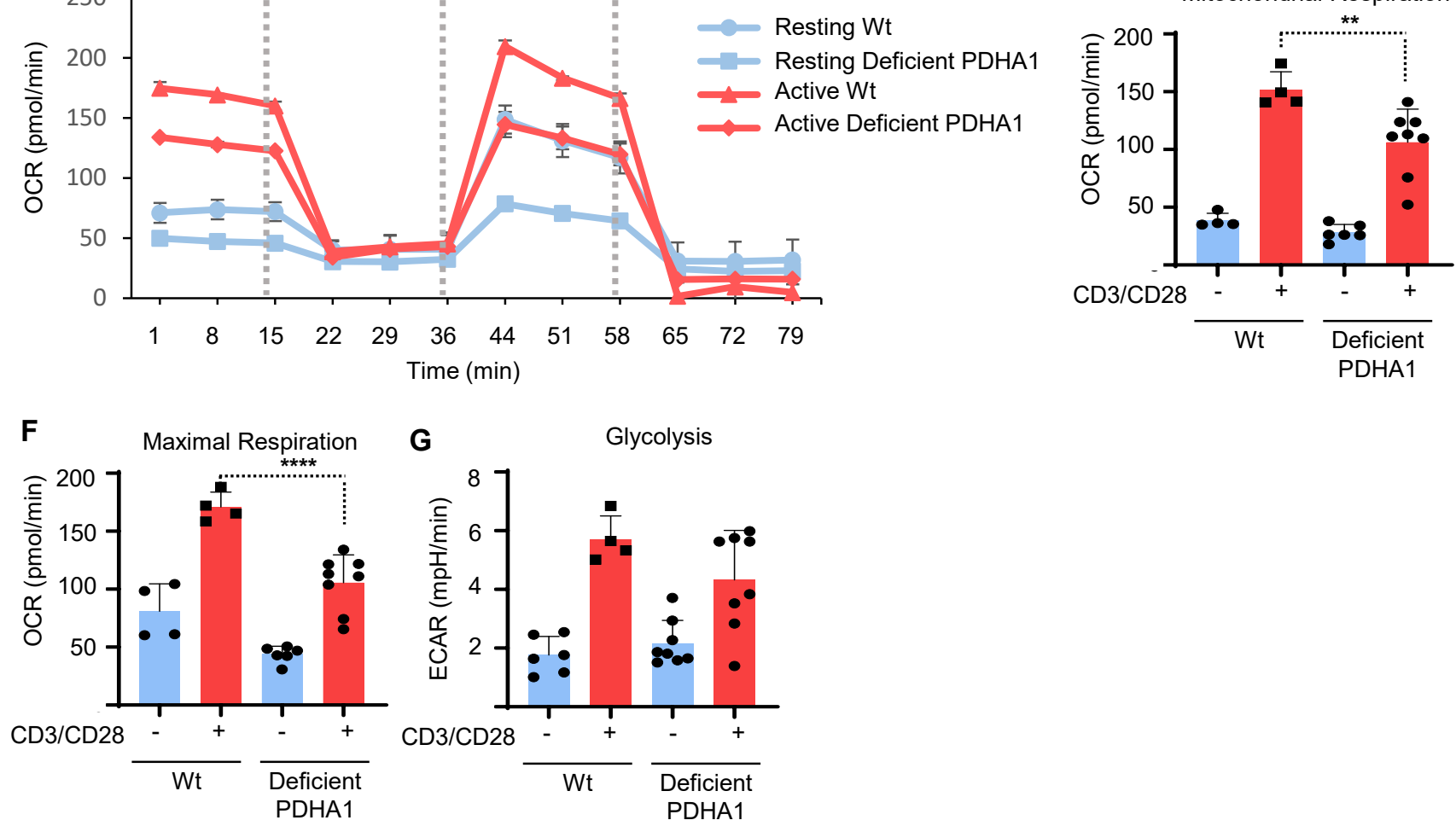

Mitochondrial Respiration 


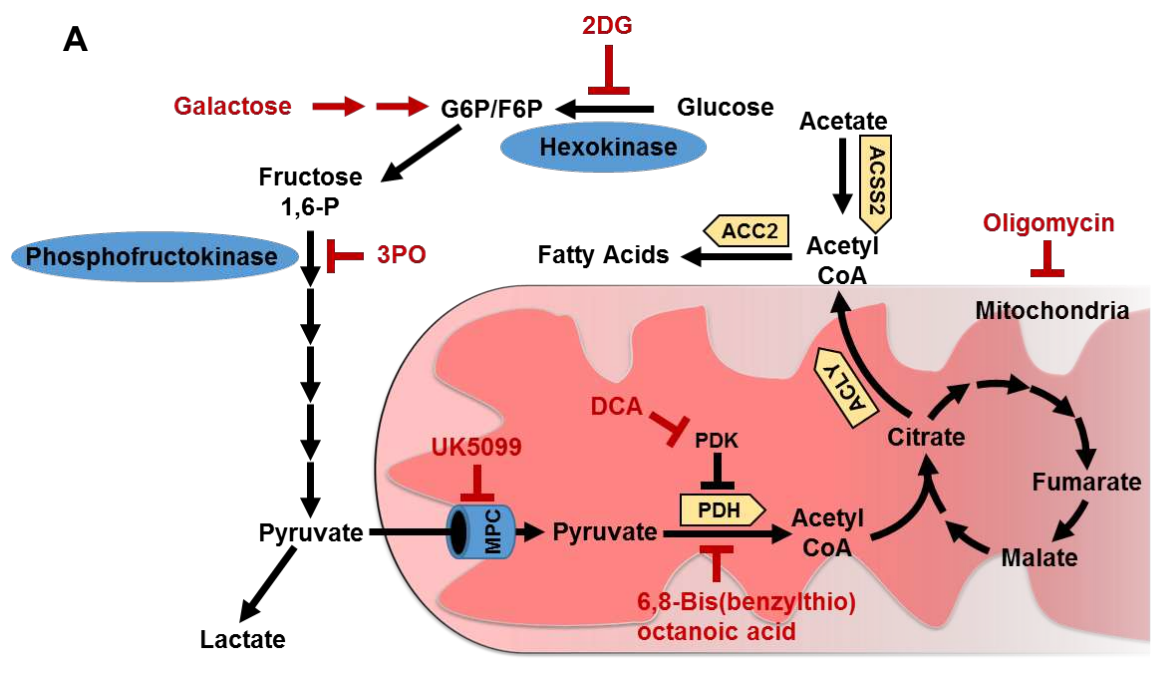

B

Glycolysis

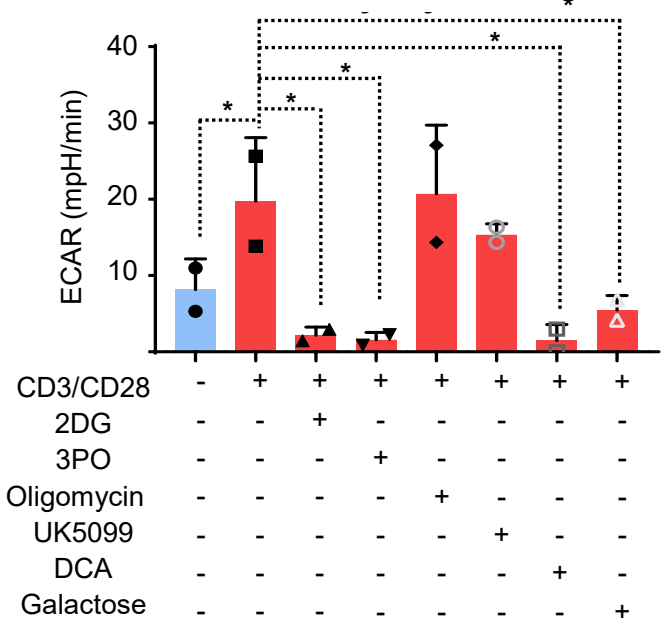

D

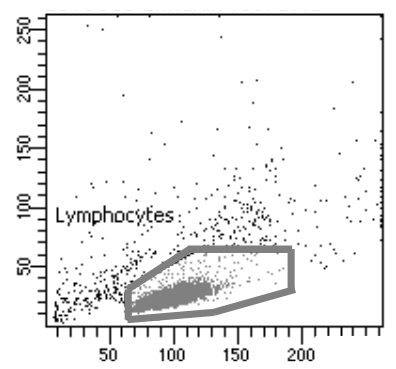

E

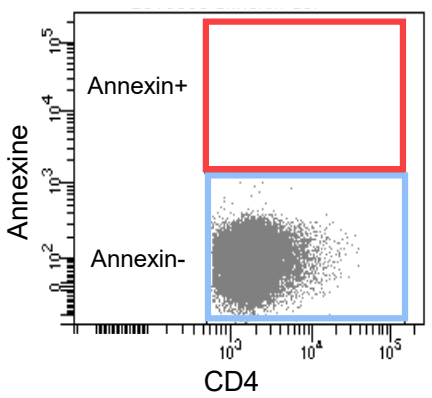

Annexin

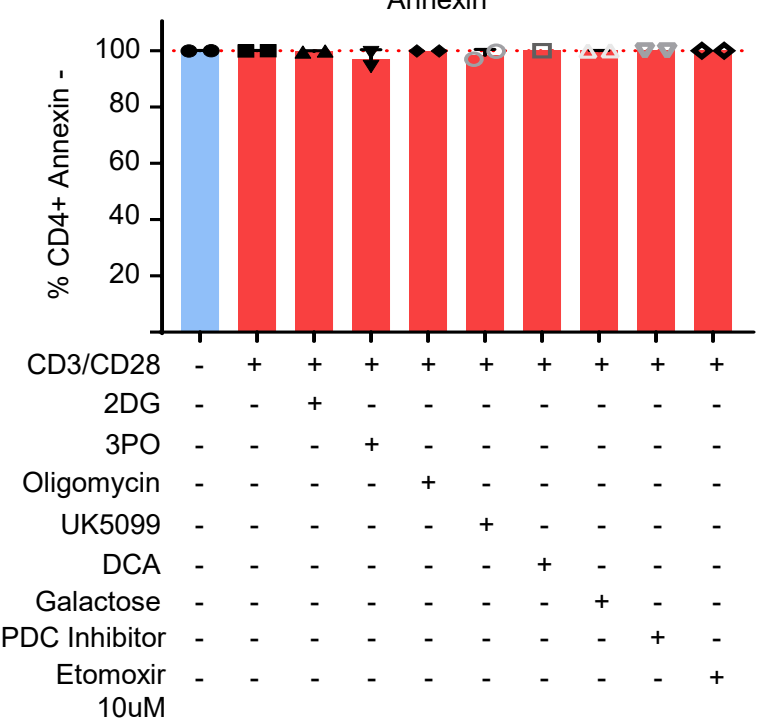

C Mitochondrial Respiration

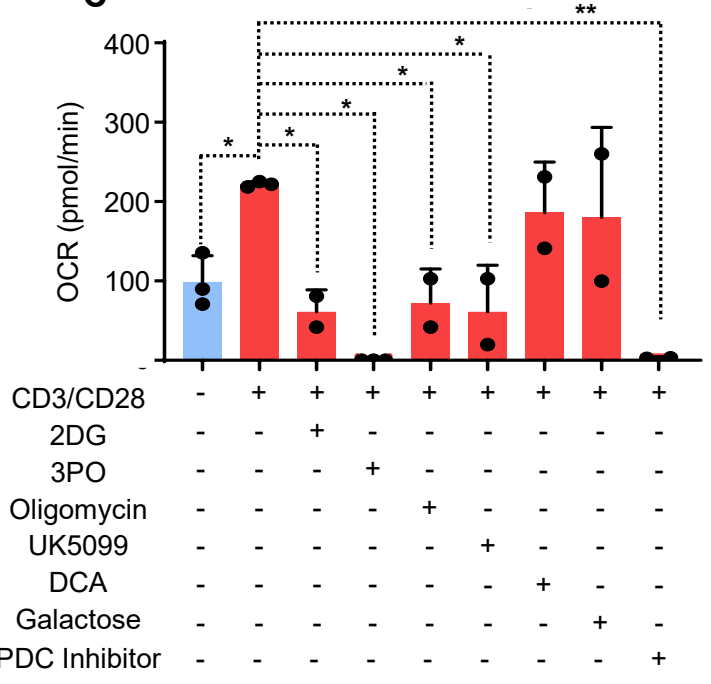

F

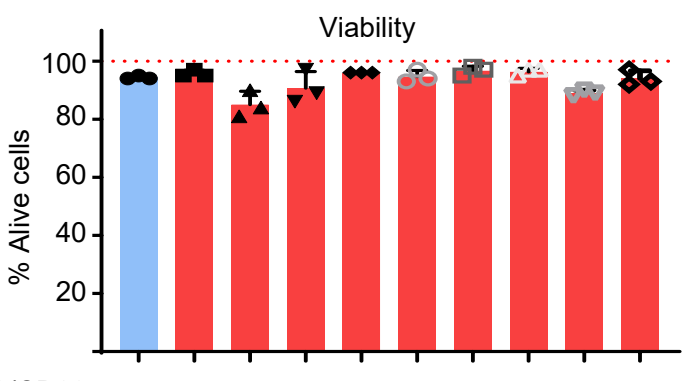

CD3/CD28

2DG

$3 \mathrm{PO}$

Oligomycin

UK5099

DCA

Galactose

PDC Inhibitor

Etomoxir

10uM 

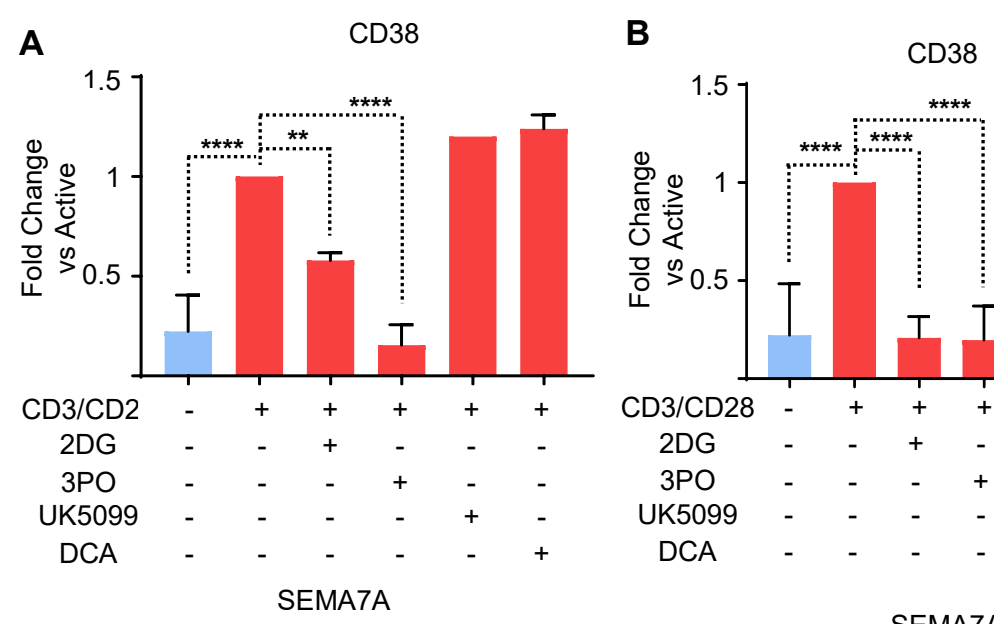

C CD38
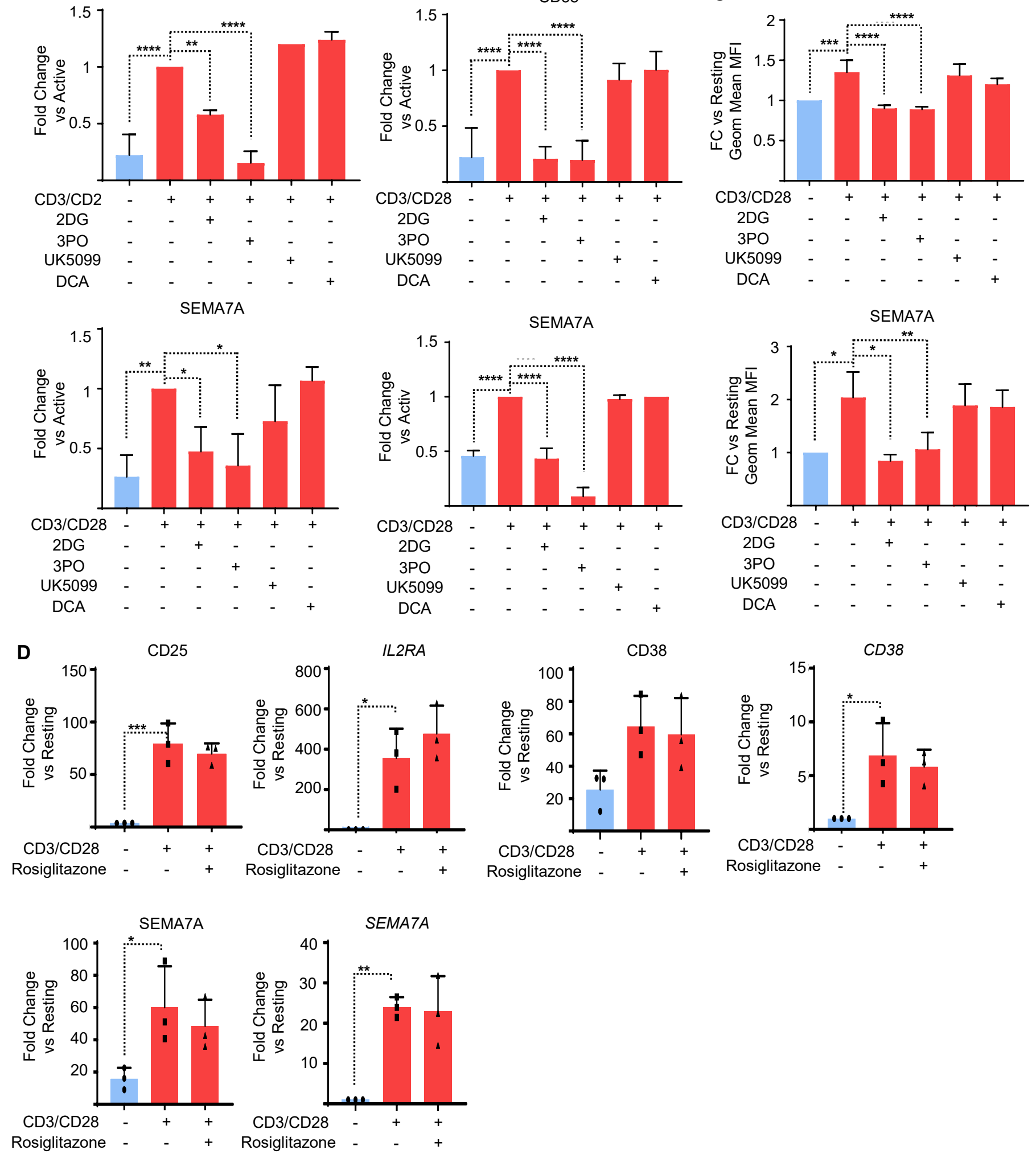


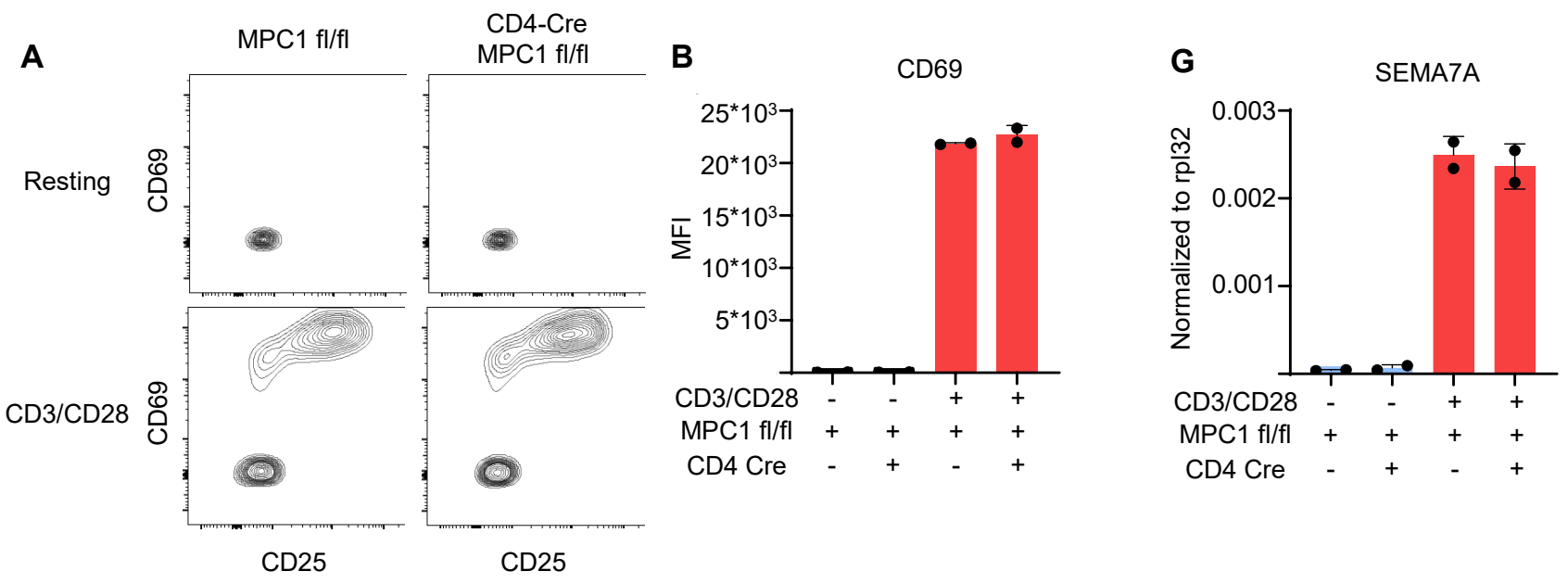




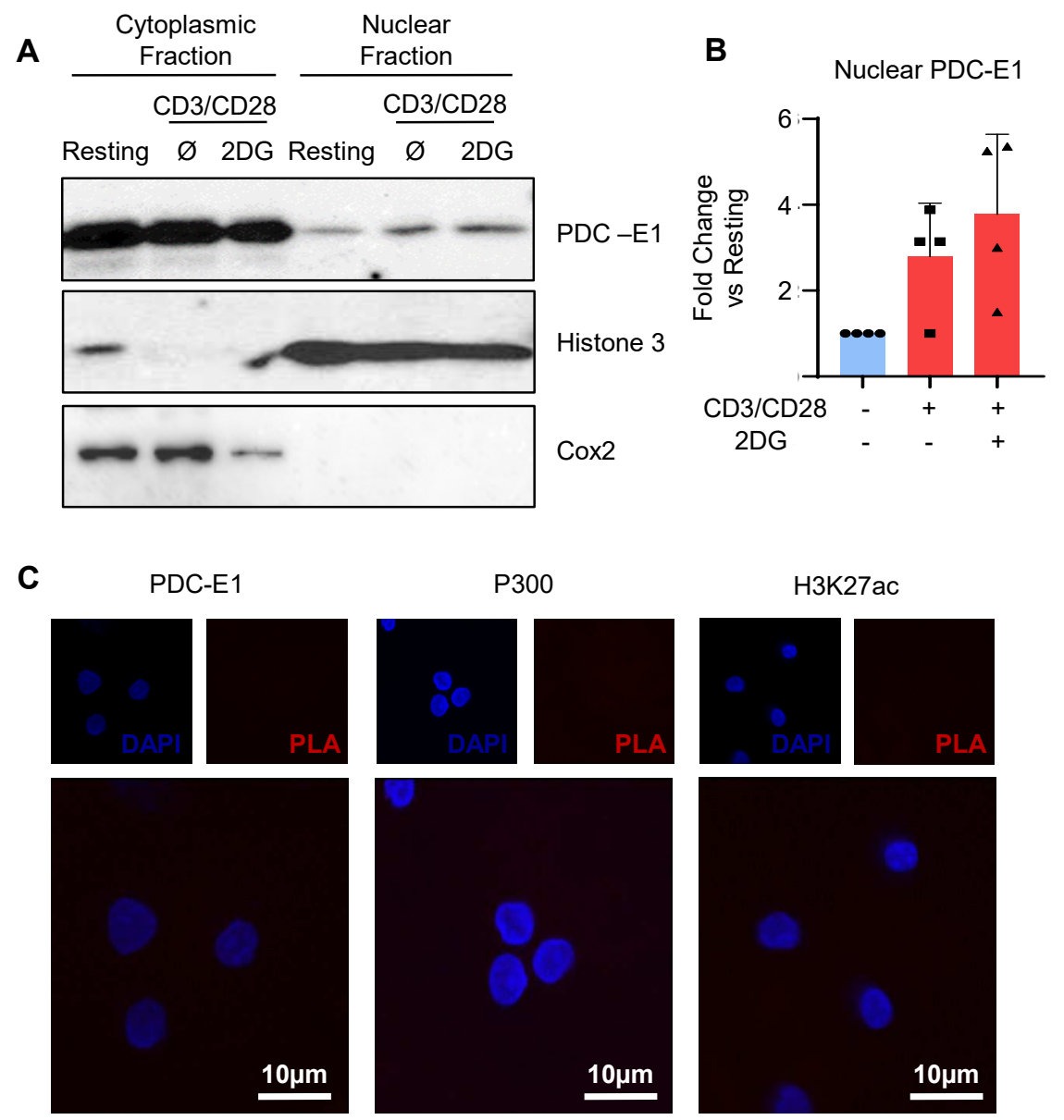


A

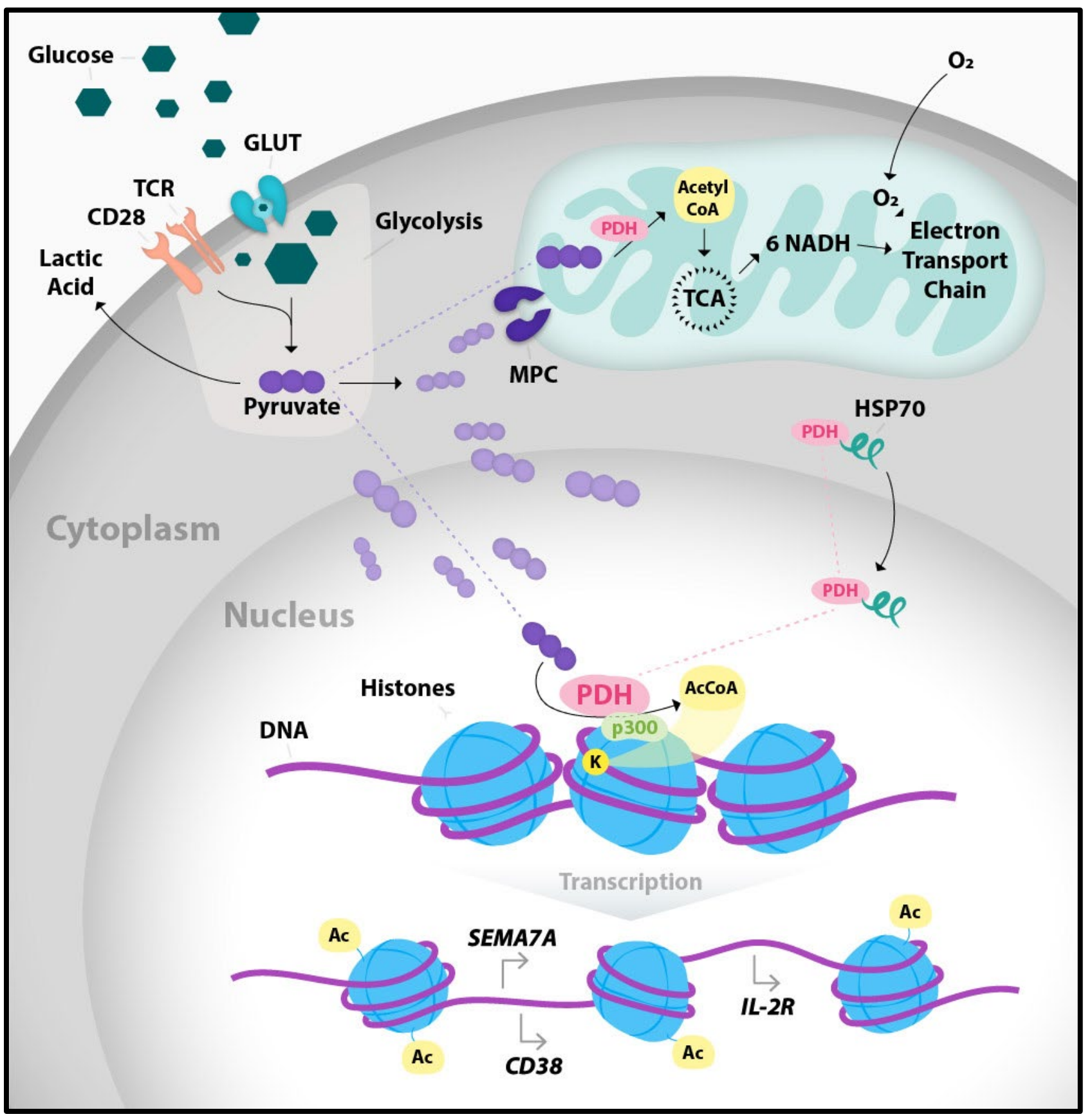

